\title{
The systematics of the Mongolepidida (Chondrichthyes) and the Ordovician origins of the clade
}

Plamen Andreev, Michael I Coates, Valentina Karatajūtè-Talimaa, Richard M Shelton, Paul R Cooper, Nian-Zhong Wang, Ivan J Sansom

The Mongolepidida is an Order of putative early chondrichthyan fish, originally erected to unite taxa from the Lower Silurian of Mongolia. The present study reassesses mongolepid systematics through the examination of the developmental, histological and morphological characteristics of scale-based specimens from the Upper Ordovician Harding Sandstone (Colorado, USA) and the Upper Llandovery-Lower Wenlock Yimugantawu (Tarim Basin, China), Xiushan (Guizhou Province, China) and Chargat (north-western Mongolia) Formations. The inclusion of the Mongolepidida within the Class Chondrichthyes is supported on the basis of a suite of scale attributes (areal odontode deposition, linear odontocomplex structure and lack of enamel, cancellous bone and hard-tissue resorption) shared with traditionally recognized chondrichthyans (euchondrichthyans, e.g. ctenacanthiforms). The mongolepid dermal skeleton exhibits a rare type of atubular dentine (lamellin) that is regarded as one of the diagnostic features of the Order within crown gnathostomes. The previously erected Mongolepididae and Shiqianolepidae families are revised, differentiated by scale-base histology and expanded to include the genera Rongolepis and Xinjiangichthys, respectively. A newly described mongolepid species (Solinalepis levis gen. et sp. nov.) from the Ordovician of North America is treated as family incertae sedis, as it possesses a type of basal bone tissue (acellular and vascular) that has yet to be documented in other mongolepids. This study extends the stratigraphic and palaeogeographic range of Mongolepidida and adds further evidence for an early diversification of the Chondrichthyes in the Ordovician Period, 50 million years prior to the first recorded appearance of euchondrichthyan teeth in the Lower Devonian. 


\section{The systematics of the Mongolepidida (Chondrichthyes)}

2 and the Ordovician origins of the clade

5 Plamen S. Andreev ${ }^{1}$, Michael I. Coates², Valentina Karatajūtè-Talimaa ${ }^{3}$, Richard M.

6 Shelton $^{4}$, Paul R. Cooper ${ }^{4}$, Nian-Zhong Wang ${ }^{5 \dagger}$ and Ivan J. Sansom ${ }^{1}$

8 'School of Geography, Earth and Environmental Sciences, University of Birmingham,

9 Edgbaston, Birmingham B15 2TT, UK

$10{ }^{2}$ Department of Organismal Biology and Anatomy, University of Chicago, Chicago, Illinois

11 60637-1508, USA

12 3Department of Geology and Mineralogy, Vilnius University, M.K. Ciurlionio 21/27, LT-03101

13 Vilnius, Lithuania

$14{ }^{4}$ School of Dentistry, College of Medical and Dental Sciences, University of Birmingham, St

15 Chad's Queensway, Birmingham B4 6NN, UK

$16{ }^{5}$ Laboratory of Evolutionary Systematics of Vertebrates, Institute of Vertebrate Palaeontology

17 and Palaeoanthropology, Chinese Academy of Sciences, PO Box 643, Beijing 100044, China;

18 deceased

19 Corresponding authors 
20 Plamen Andreev, p.andreev@bham.ac.uk

21 Ivan Sansom, i.j.sansom@bham.ac.uk

\section{ABSTRACT}

23 The Mongolepidida is an Order of putative early chondrichthyan fish, originally erected

24 to unite taxa from the Lower Silurian of Mongolia. The present study reassesses

25 mongolepid systematics through the examination of the developmental, histological

26 and morphological characteristics of scale-based specimens from the Upper

27 Ordovician Harding Sandstone (Colorado, USA) and the Upper Llandovery-Lower

28 Wenlock Yimugantawu (Tarim Basin, China), Xiushan (Guizhou Province, China) and

29 Chargat (north-western Mongolia) Formations.

30 The inclusion of the Mongolepidida within the Class Chondrichthyes is supported on

31 the basis of a suite of scale attributes (areal odontode deposition, linear

32 odontocomplex structure and lack of enamel, cancellous bone and hard-tissue

33 resorption) shared with traditionally recognized chondrichthyans (euchondrichthyans,

34 e.g. ctenacanthiforms). The mongolepid dermal skeleton exhibits a rare type of

35 atubular dentine (lamellin) that is regarded as one of the diagnostic features of the

36 Order within crown gnathostomes.

37 The previously erected Mongolepididae and Shiqianolepidae families are revised,

38 differentiated by scale-base histology and expanded to include the genera Rongolepis

39 and Xinjiangichthys, respectively. A newly described mongolepid species (Solinalepis

40 levis gen. et sp. nov.) from the Ordovician of North America is treated as family 
41 incertae sedis, as it possesses a type of basal bone tissue (acellular and vascular)

42 that has yet to be documented in other mongolepids.

43 This study extends the stratigraphic and palaeogeographic range of Mongolepidida

44 and adds further evidence for an early diversification of the Chondrichthyes in the

45 Ordovician Period, 50 million years prior to the first recorded appearance of

46 euchondrichthyan teeth in the Lower Devonian.

47

48

49 
60 Keywords Mongolepids, Solinalepis gen. nov., Palaeozoic, Scales, Morphogenesis,

61 Odontocomplex

\section{INTRODUCTION}

Middle Ordovician to upper Silurian strata have yielded a number of isolated scale remains that have been assigned to the chondrichthyans with varying degrees of confidence. This 50 million year record pre-dates the first appearance of teeth and

67 articulated skeletons (Leonodus and Celtiberina Botella et al., 2009; Doliodus Miller,

68 Cloutier \& Turner, 2003; Maisey, Miller \& Turner, 2009 and Antarctilamna Young,

69 1982) of traditionally recognized chondrichthyans (euchondrichthyans sensu Pradel et

al, 2014), as well as body fossils of acanthodian-grade stem chondrichthyans

71 (Brazeau \& Friedman, 2015 and references therein). These, largely microscopic, remains include the elegestolepids (Karatajūtè-Talimaa, 1973; Žigaitė \& KaratajūtèTalimaa, 2008; Andreev et al., in press), sinacanthids (Zhu, 1998; Sansom, Wang \& Smith, 2005), taxa such as Tezakia and Canyonlepis from the Ordovician of North America (Sansom, Smith \& Smith, 1996; Andreev et al., 2015), Tantalepis (Sansom et al., 2012), Kannathalepis (Märss \& Gagnier, 2001) and Pilolepis (Thorsteinsson,

77 1973), and, perhaps the most widely distributed and diverse collection of what Ørvig 78 and Bendix-Almgreen, quoted in Karatajūtè-Talimaa (1995), referred to as 
79 'praechondrichthyes', the mongolepids (Karatajūtè-Talimaa et al., 1990; Karatajūtè-

80 Talimaa \& Predtechneskyj, 1995; Sansom, Aldridge \& Smith, 2000). It is the latter

81 which this work concentrates on, re-assessing and re-defining previously described

82 members of the Mongolepidida, and describing a new taxon that extends the range of

83 the Order into the Ordovician, adding further evidence for a diversification of early

84 chondrichthyans as part of the Great Ordovician Biodiversification Event that

85 encompasses a wide variety of taxa, both invertebrate (e.g. Webby, Paris \& Droser,

86 2004; Servais et al., 2010) and vertebrate (Sansom, Smith \& Smith, 2001; Turner,

87 Blieck \& Nowlan, 2004).

88 Previous work on mongolepids

89 Mongolepids were first described by Karatajūtè-Talimaa et al. (1990) and Karatajūtè-

90 Talimaa (1995) from the Chargat Formation (Upper Llandovery-Lower Wenlock) in

91 north-western Mongolia, together with a diverse assemblage of early vertebrates

92 including pteraspidomorphs (Karatajūtè-Talimaa, unpublished data), thelodonts

93 (Žigaitè, 2004, 2013; Žigaitè, Karatajūtè-Talimaa \& Blieck, 2011), acanthodians

94 (Karatajūtè-Talimaa \& Smith, 2003) and elegestolepids. The first erected species,

95 Mongolepis rozmanae, was subsequently added to with the description of Teslepis

96 jucunda Karatajūtè-Talimaa \& Novitskaya (1992) and Sodolepis lucens Karatajūtè-

97 Talimaa \& Novitskaya (1997), also from the Chargat Formation. Recently the

98 stratigraphic ranges of Mongolepis and Teslepis have been extended to include

99 Aeronian (Middle Llandovery) and Sheinwoodian (Lower Wenlock) sedimentary

100 sequences from Altai and Tuva (Sennikov et al., 2015). Shiqianolepis hollandi from the 
101 Xiushan Formation (Telychian) of south China was also placed within the Order by

102 Sansom, Aldridge \& Smith (2000), although a new Family, the Shiqianolepidae, was

103 erected based upon an interpretation of the scale growth patterns within mongolepids.

104 Additional material from the upper Llandovery of the Tarim Basin (Xinjiang Uygyr

105 Autonomous Region, north-west China) is also referable to the group (unpublished

106 data). Thus, to date, the distribution of mongolepids has been limited to a very narrow

107 time frame (Llandovery-Wenlock) and is concentrated within the Mongol-Tuva, Altai,

108 South China and Tarim tectonic blocks. The taxonomic placement of the group has

109 been greatly hampered by the absence of articulated specimens that exhibit any

110 anatomical detail of the mongolepid bodyplan (Karatajūtè-Talimaa et al., 1990;

111 Karatajūtè-Talimaa, 1995).

112

113 MATERIALS AND METHODS

114 All examined material consists of isolated scales extracted by petroleum ether or

115 acetic acid disaggregation of rock samples from the Sandbian Harding Sandstone of

116 central Colorado, USA, the Upper Llandovery-Lower Wenlock Chargat Formation of

117 north-western Mongolia, the lower and upper members of the Telychian Yimugantawu

118 Formation of Xinjiang (Tarim Basin, China) and the lower Member of the Telychian

119 Xiushan Formation (Guizhou Province, China).

120 Scale morphology was documented using the JEOL JSM-6060 and Zeiss EVO

121 LS scanning electron microscopes at the School of Dentistry of the University of 
122 Birmingham, UK. Prior to imaging specimens were sputter-coated with gold/palladium

123 alloy.

124 For the purpose of studying scale histology and internal structure, doubly

125 polished thin sections of scales were examined with Nomarski differential interference

126 contrast microscopy (using a 'Zeiss Axioskop Pol' polarization microscope) and

127 scanning electron microscopy (using a JEOL JSM-6060 SEM at the School of

128 Dentistry, University of Birmingham, UK).

129 Scale examination with X-ray radiation was performed with the SkyScan 1172

130 microtomography scanner at the School of Dentistry, University of Birmingham, UK.

131 The acquired microradiographs (tomographic projections) were taken at $0.3^{\circ}$ intervals

132 over a $180^{\circ}$ rotation cycle at exposure times of $400 \mathrm{~ms}$, using a $0.5 \mathrm{~mm}$ thick X-ray

133 attenuating Al filter. These image data were processed with the SkyScan NRecon

134 reconstruction software for the purpose of generating sets of microtomograms that

135 were converted into volume renderings in Amira 5.4 3D analysis software.

136 Figured specimens are housed in the Lapworth Museum of Geology, University

137 of Birmingham, UK (BU prefix), the Nanjing Institute of Geology and Palaeontology,

138 Chinese Academy of Sciences, Nanjing, China (NIGP prefix) and the Institute of

139 Vertebrate Paleontology and Paleoanthropology, Chinese Academy of Sciences,

140 Beijing, China (IVPP V prefix). The examined non-figured scales have not been given

141 collection numbers. Additional mongolepid material, alluded to but not described in this

142 work (referred to as unpublished data above), from the Tarim Basin of China is housed 
143 in and registered at the Institute of Vertebrate Paleontology and Paleoanthropology,

144 Chinese Academy of Sciences.

145 The electronic version of this article in Portable Document Format (PDF) will represent a

146 published work according to the International Commission on Zoological Nomenclature

147 (ICZN), and hence the new names contained in the electronic version are effectively

148 published under that Code from the electronic edition alone. This published work and

149 the nomenclatural acts it contains have been registered in ZooBank, the online

150 registration system for the ICZN. The ZooBank LSIDs (Life Science Identifiers) can be

151 resolved and the associated information viewed through any standard web browser by

152 appending the LSID to the prefix http://zoobank.org/. The LSID for this publication is:

153 urn:Isid:zoobank.org:pub:3C24AE11-1F12-4B16-B04D-480CA204CCEA. The online

154 version of this work is archived and available from the following digital repositories:

155 PeerJ, PubMed Central and CLOCKSS.

156

157 Definitions of terms

158 The interpretations of the terms (Fig. 1) employed in the descriptions of fossil scales

159 follow Andreev et al. (2015). The rationale behind this is to improve identification of

160 homologous scale structures across taxa by introducing a standardized terminology.

161

162 Results

163 Systematic Palaeontology 
164 Class CHONDRICHTHYES Huxley, 1880

165 Order MONGOLEPIDIDA Karatajūtè-Talimaa, Novitskaya, Rozman \& Sodov, 1990

166 Included Families

167 Mongolepididae Karatajūtè-Talimaa et al., 1990

168 Shiqianolepidae Sansom, Aldridge \& Smith, 2000

169 Emended diagnosis

170 Polyodontode growing scale crowns formed by multiple antero-posteriorly oriented

171 primary odontocomplex rows. Odontode size within each row increases gradually

172 towards the posterior of the scale. Individual odontodes formed exclusively of

173 inotropically and spheritically mineralised atubular, acellular dentine (lamellin).

\section{Remarks}

175 The current study has determined scale crown growth (sensu Reif, 1978) to be a

176 characteristic shared by all mongolepid taxa (see Discussion for details), contrary to

177 previous interpretations of synchronomorial development of scale odontodes in

178 Mongolian mongolepid species (Karatajūtè-Talimaa et al., 1990; Karatajūtè-Talimaa \&

179 Novitskaya, 1992, 1997). Under the revised definition of the Order, the Mongolepidida

180 retains the Families Mongolepididae (Karatajūtè-Talimaa et al., 1990) and

181 Shiqianolepidae (Sansom, Aldridge \& Smith, 2000), yet contra Sansom, Aldridge \&

182 Smith (2000) these are newly differentiated on the basis of base histology (see below)

183 and are expanded to also include the genera Rongolepis Sansom, Aldridge \& Smith,

1842000 and Xinjiangichthys Wang et al., 1998, respectively. Solinalepis levis gen. et sp. 
185 nov. is also added to the Order, but placed within incertae sedis at Family-grade due

186 to the absence of clearly defined characters at this taxonomic level.

188 Family MONGOLEPIDIDAE Karatajūtè-Talimaa, Novitskaya, Rozman \& Sodov, 1990

189 Included genera

190 Mongolepis Karatajūtè-Talimaa, Novitskaya, Rozman \& Sodov, 1990

191 Teslepis Karatajūtè-Talimaa \& Novitskaya, 1992

192 Sodolepis Talimaa \& Novitskaya, 1997

193 Rongolepis Sansom, Aldridge \& Smith, 2000

194 Emended diagnosis

195 Mongolepids possessing bulging scale bases composed of acellular bone tissue with

196 cross-ply architecture.

\section{Remarks}

198 Scale-derived phylogenetic data (Fig. 2; Andreev, Coates \& Sansom, unpublished)

199 identify two monophyletic groups inside Mongolepidida distinguished by differences in

200 the bone histology and morphology of the scale base. These substitute the scale-

201 crown developmental characteristics that have been used previously by Sansom,

202 Aldridge \& Smith (2000) to establish the Family structure of the Mongolepidida. 
204 Genus MONGOLEPIS Karatajūtè-Talimaa, Novitskaya, Rozman \& Sodov, 1990

205 Type and only species

206 Mongolepis rozmanae Karatajūtè-Talimaa et al. 1990, from the Chargat Formation,

207 Salhit regional Stage (Upper Llandovery-Lower Wenlock) of north-western Mongolia.

208 Non-figured M. rozmanae and M. sp. specimens have been reported (Sennikov et al.,

209 2015) from the Aeronian (Middle Llandovery) Sadra section (Gornaya Shoriya, Altai

210 Republic, Russia) and the Sheinwoodian (Lower Wenlock) Upper Tarkhata

211 Subformation (Charygka horizon, Gorny Altai, Altai Republic, Russia) and Baytal

212 Formation (Pichishui Horizon, Tuva Republic, Russia).

\section{Diagnosis}

214 As for the type species.

216 MONGOLEPIS ROZMANAE Karatajūtè-Talimaa, Novitskaya, Rozman \& Sodov, 1990

217 (Figs. 1, 3A-D, 6A-E, 8A-C, 9D)

2181990 Mongolepis rozmanae Karatajūtè-Talimaa, Novitskaya, Rozman \& Sodov, figs.

$2192-5$, pl. IX.

2201992 Mongolepis rozmanae Karatajūtè-Talimaa \& Novitskaya, fig. 2ж, 3.

2211995 Mongolepis rozmanae Karatajūtè-Talimaa, fig. 1.

2221998 Mongolepis rozmanae Karatajūtè-Talimaa, figs. 11, 20. 


\section{Emended diagnosis}

225 Mongolepidids (pertaining to Mongolepididae) possessing large scales (up to over 3

$226 \mathrm{~mm}$ ), constricted along their anterior margin, containing a large number of primary

227 odontocomplex rows (up to 50+) with long, sigmoidal odontodes. Inter-odontocomplex

228 spaces divided into pore-like compartments by short, transverse struts. Bulbous base

229 with a prominent crescent-shaped anterior platform that forms below the level of the

230 crown surface and extends laterally into two spine-shaped processes.

\section{Holotype}

232 An ontogenetically mature scale (LGI M-1-031) deposited in collection LGI M-1 of the

233 Lithuanian Geological Survey, Vilnius (Karatajūtè-Talimaa et al., 1990).

\section{Referred material}

235 Hundreds of isolated scales from the type locality (from samples P-16/3 and ЦГЭ

236 N1009). Non-figured specimens examined for this study are stored in the

237 microvertebrate research collection of the Lapworth Museum of Geology, University of

238 Birmingham, UK.

\section{Description}

\section{Morphology}

241 Primary odontodes from the same position in the crown are of equal size irrespective

242 of scale dimensions. The number of odontocomplex rows changes with the

243 proportions of the crown and its size, with scales of up to $2 \mathrm{~mm}$ in length usually 
244 possessing less than 20 odontocomplexes, whereas in larger specimens their number 245 varies from 20 to c. 35.

246 Primary odontodes exhibit posteriorly curved profiles and an incremental

247 increase in length towards the posterior of the scale (Figs. 6A, B, 9D). This creates a 248 significant height difference (over five fold in medial odontocomplexes) between the

249 anterior- and the posterior-most elements of primary odontocomplexes, whilst

250 odontode thickness remains relatively constant at c. $50 \mu \mathrm{m}$ (Figs. 6A, B, 9D). The

251 crown surface profile is planar (Fig. 3A, B, D) due to a gradual decrease in the angle

252 of odontode curvature towards the posterior of the scale, accompanied by sloping of

253 the crown/base contact surface (Figs. 6A, 9D).

254 In scales larger than $1 \mathrm{~mm}$, secondary odontodes are developed to a varying 255 extent along the anterior margin of the crown (Fig. 3A, B, D). These are arranged into 256 rows and are undivided by inter-odontode spaces (Fig. 3A, B, D). In common with the

257 main crown odontodes, the secondary odontodes are posteriorly arched elements that 258 demonstrate an unidirectional increase in length (Figs. 6A-B, 9D); the latter being 259 expressed towards the anterior end of the scale.

The scale bases are bulbous structures (Fig. $3 A-C$ ) that reach their maximum

261 thickness directly under the anterior apex of the crown. To the posterior, the majority

262 of scale bases display a pitted lower-base surface produced by series of canal

263 openings (Fig. 3B, C).

\section{Histology}


265 Scale odontodes are composed of atubular dentine (Fig. 6A-C) for which Karatajūtè-

266 Talimaa et al. (1990) used the term lamellin (first introduced by Bolshakova and

267 Ulitina, 1985). Within individual odontodes, the lamellin displays two histologically

268 distinct regions - a peripheral (10-20 $\mu \mathrm{m}$ thick) lamellar zone and an inner region

269 dominated by mineralised spherites united within Liesegang waves (Fig. 6C; for a

270 definition refer to (Ørvig 1951)). The diameter of the calcospherites changes randomly

271 but rarely exceeds $15 \mu \mathrm{m}$.

Primary odontode pulps are either closed off or can be greatly constricted by

273 dentine infill (Figs. 6A, 8C) yet remaining open at their lower end, from which emerges

274 a pair of short (c. $15 \mu \mathrm{m})$ horizontal canals that connect the pulp cavity to the

275 odontode surface (Fig. 8C, C1). The foramina of these canals face either the inter-

276 odontocomplex spaces or, in marginal odontodes, are exposed at the periphery of the

277 crown (Fig. 3A).

278

In a similar manner to primary odontocomplexes, the pulps of secondary

odontodes are substantially constricted by dentine deposition, but they lack the

280

network of horizontal canals (Figs. 3A, B, 8C) developed inside the rest of the crown.

The scale base consists of acellular bone characterized by a succession of convex-down growth lamellae (up to $150 \mu \mathrm{m}$ thick; Fig. 6A, D, 9D) that increase in

283 extent towards the lower portion of the tissue. Secondary lamination is evident within

284 these primary depositional structures and is produced by intrinsic mineralised fibres

285 (sensu Ørvig, 1966) of c. $2 \mu \mathrm{m}$ diameter, which likewise demarcate the boundary

286 surfaces of primary lamellae (Fig. 6D). The basal bone also contains elaborately 
287 organised extrinsic crystalline fibres (sensu Ørvig, 1966) of c. $2 \mu \mathrm{m}$ diameter (Fig. 6A,

288 E), which have the appearance of hollow cylindrical rods (Fig. 5E). These are grouped

289 into layers oriented obliquely with respect to one another (Fig. 6A, E, 9D), that

290 propagate through the tissue. The layers exhibit straight to upwardly arching profiles

291 and thickness of c. 50-70 $\mu \mathrm{m}$ (Fig. 6A, D, E; 9D).

The base houses a vascular system represented by curved (both anteriorly and posteriorly) large-calibre vertical canals (c. $100 \mu \mathrm{m}$; Fig. 8A, B) that are split at their upper end into two or more rami, each merging with one of the primary odontode pulps. Conversely, the secondary odontode pulps are not connected to the canal system of the base.

\section{Remarks}

298 In contrast to earlier work on Mongolepis (Karatajūtè-Talimaa et al., 1990; Karatajūtè-

299 Talimaa, 1998), the present study reinterprets the pattern of scale ontogenesis of the

300 genus. Recorded size differences between Mongolepis scales have been used by

301 previous authors (Karatajūtè-Talimaa et al., 1990; Karatajūtė-Talimaa, 1998) to

302 identify four distinct ontogenetic stages in the development of the scale cover. They

303 have suggested synchronomorial crown growth succeeded by incremental deposition

304 of basal bone to characterise the scale morphogenesis of Mongolepis, with scales of

305 ever-increasing crown size and base thickness assumed to be added at each stage of

306 scale cover ontogeny. A re-examination of Mongolepis specimens has revealed the

307 presence of bases across the spectrum of documented scale sizes. Furthermore,

308 specimens in the sub-millimetre size category, corresponding to the papillary and 
309 juvenile scales of Karatajūtè-Talimaa et al. (1990), possess bases that are

310 proportionally as thick as those of larger scales. Thus, scales interpreted as being

311 composed exclusively of odontodes (Karatajūtè-Talimaa, 1998, fig. 11A2, E) were

312 related to specimens where the bases had been abraded away. This new

313 morphological evidence supports incremental and mutually synchronous deposition of

314 Mongolepis crown and base scale components. The odontocomplex structure and

315 base depositional lamellae of Mongolepis scales are similarly identified in all

316 mongolepid genera and indicate that cyclomorial scale growth, achieved via

317 sequential areal addition of odontodes (sensu Sansom, Aldridge \& Smith (2000),

318 originally defined by Stensiö (1961)), is a characteristic of the Mongolepidida (see

319 Discussion for details).

320

321 Genus TESLEPIS Karatajūtè-Talimaa \& Novitskaya, 1992

322 Type and only species

323 Teslepis jucunda Karatajūtè-Talimaa \& Novitskaya, 1992, from the Chargat Formation

324 (Salhit regional Stage, Upper Llandovery-Lower Wenlock) of north-western Mongolia.

325 Non-figured T. jucunda specimens have been reported (Sennikov et al., 2015) from

326 the Aeronian (Middle Llandovery) Sadra section (Gornaya Shoriya, Altai Republic,

327 Russia) and the Sheinwoodian (Lower Wenlock) Upper Tarkhata Subformation

328 (Charygka horizon, Gorny Altai, Altai Republic, Russia).

\section{Diagnosis}


330 As for the type species.

331

332 TESLEPIS JUCUNDA Karatajūtė-Talimaa \& Novitskaya, 1992

333 (Figs. 3E-G, 6F, 8D, 9A)

3341992 Teslepis jucunda Karatajūtè-Talimaa \& Novitskaya, figs. 1, 2a-e, 3, 4, pl. V figs. $3351-8$.

3361992 Teslepis sp. Karatajūtè-Talimaa \& Novitskaya, pl. V fig. 9.

3371998 Teslepis jucunda Karatajūtè-Talimaa, fig. 19.

338 Emended diagnosis

339 Mongolepidids with small scales whose odontocomplex number increases with scale

340 size. Non-odontode atubular globular dentine developed at the anterior and lateral

341 crown margins. Scale base extended into an antero-basally directed conical

342 projection.

343 Holotype

344 An ontogenetically mature scale (LGI M-1-077) deposited in collection LGI M-1 of the

345 Lithuanian Geological Survey, Vilnius (Karatajūtè-Talimaa \& Novitskaya, 1992).

\section{Material}

347 Several hundred isolated scales from the type locality (from samples P-16/3 and ЦГЭ

348 N1009). Non-figured specimens examined for this study are stored in the

349 microvertebrate research collection of the Lapworth Museum of Geology, University of

350 Birmingham, UK. 


\section{Description}

\section{Morphology}

354 The number of the scale odontocomplex rows is related to crown size and its

355 proportions. In small specimens (less than $0.5 \mathrm{~mm}$ long) their number varies from 4 to

3566 , whilst it reaches 17 in scales larger than $1 \mathrm{~mm}$. Within the individual

357 odontocomplexes the odontode length gradually increases in a posterior direction (Fig.

$3586 \mathrm{~F}$ ), whereas odontode thickness remains relatively constant at c. $50 \mu \mathrm{m}$.

In the majority of specimens a crescent-shaped platform (Fig. 3E, F) is formed anterior to the odontocomplexes, and the former can be elevated slightly above the

361 level of the odontodes. The absence of this thickening does not correlate with a

362 particular scale size.

The base is not constricted at the contact with the crown (Fig. 3E-G) and extends away from this junction into an anteriorly-directed conical projection that protrudes beyond the crown margin. The posterior third of the base is shallower in

366 comparison with its thickened anterior (Fig. 6F), and is marked by rows of canal

367 openings (30-60 $\mu \mathrm{m}$ in diameter; Fig. 3G) aligned with the odontocomplexes of the 368 crown.

\section{Histology}

370 The crown odontodes consist of atubular dentine (lamellin; Fig. 6F) having a

371 predominately lamellar periphery and an inner spheritically mineralised region. The 
372 calcospherites of the globular lamellin attain a diameter of approximately $10 \mu \mathrm{m}$ and

373 comprise of concentric Liesegang rings closed around a central cavity. These exhibit

374 linear or concave arrested growth contact surfaces with other spherites and adjacent

375 Liesegang waves. The scale odontodes possess vascular spaces in the form of

376 vestiges of pulp canals that are mostly filled by lamellin. The pulps branch out laterally

377 as paired short horizontal canals (diameter $10-15 \mu \mathrm{m}$ ) that open on the odontode

378 surface (Fig. 8D, D1).

A structural variety of atubular dentine different from lamellin forms the crown

380 platform that surmounts the thickest part of the base (Fig. 6F). This tissue exhibits

381 exclusively spheritic mineralisation represented by tightly packed globules (up to 10

$382 \mu \mathrm{m}$ in diameter), and lacks a canal system.

383

The basal bone is acellular with a series of depositional lamellae demarcated

384 by basally arched intrinsic fibres (Fig. 6F). The smallest lamellae reside at the level of

385 the anterior-most odontodes, with lamella thickness varying from $15 \mu \mathrm{m}$ to $20 \mu \mathrm{m}$

386 across the extent of the tissue.

The basal bone contains extrinsic mineralised fibres grouped into $20-40 \mu \mathrm{m}$ thick layers with upwardly curved profiles. The fibres within each layer are mutually parallel but also oriented obliquely to those of adjacent lamellae, giving the bone a

390 plywood-like texture. In addition to the abundant fibres with layered organization, the

391 tissue contains a set of extrinsic, vertically oriented fibres (Fig. 6F) that are evenly

392 spaced at about $5 \mu \mathrm{m}$ intervals and propagate up to the level of the crown-base 393 junction. 
The base is penetrated by a number of large-calibre vertical vascular canals

395 (Fig. 8D, D1), which connect with the pulp cavities of crown odontodes. The former

396 are predominantly preserved in the posterior (thinnest) third of the base as anteriorly

397 arching canals that gradually widen to c. $40 \mu \mathrm{m}$ at the lower base surface (Fig. 8D, 398 D1).

\section{Remarks}

400 The anterior crown platform of Teslepis scales (developed also in Sodolepis) received

401 little attention in the descriptions of Karatajūtè-Talimaa \& Novitskaya (1992) and

402 Karatajūtè-Talimaa (1998), apart from being identified as composed of an

403 undetermined type of globular basal tissue. The platform always forms at the level of

404 the primary odontodes and sutures to the anterior most of them, developing in the

405 space typically occupied by secondary odontodes in Mongolepis, Rongolepis,

406 Xinjiangichthys and Shiqianolepis scales. From a histological perspective, the lack of

407 lamellar matrix and the predominantly arrested-growth contact surfaces of spherites

408 resemble the microstructure of certain types of spheritically mineralized dentine

409 (Schmidt \& Keil, 1971, fig. 46, 47). Consequently, this tissue is regarded to be globular

410 atubular dentine as opposed to globular dermal bone that is commonly formed only in

411 the cavity-rich cancellous zone of the exoskeleton of lower vertebrates (Ørvig, 1968;

412 Donoghue, Sansom \& Downs, 2006; Downs \& Donoghue, 2009).

413 Contrasting with the well-defined and consistent shape of the odontodes, the

414 anterior platform has an irregular surface and poorly defined boundaries, and whose

415 shape is determined by the contours of the underlying base. As a consequence, it 
416 could be suggested that this mass of globular dentine is not the product of a well-

417 differentiated dermal papilla, which typifies early odontode development and

418 determines the morphology of odontodes independently of that of the basal bone

419 (Sire, 1994; Sire \& Huysseune, 1996; Sire \& Huysseune, 2003). Outside Teslepis and

420 Sodolepis, dentine structures with similar characteristics have not been documented in

421 the integumentary skeleton of gnathostomes.

Cellular basal bone was considered by Karatajūtè-Talimaa \& Novitskaya (1992)

423 to be a diagnostic characteristic of Teslepis in the original description of the genus.

424 Fusiform odontocyte lacunae identified in that study are considered herein to

425 represent hollow interiors of mineralised fibres of within bone matrix (the implications

426 of this revised interpretation are expanded on in the Discussion).

427

428 Genus SODOLEPIS Karatajūtè-Talimaa \& Novitskaya, 1997

429 Type and only species

430 Sodolepis lucens Karatajūtè-Talimaa \& Novitskaya, 1997, from the Chargat Formation

431 (Salhit regional Stage, Upper Llandovery-Lower Wenlock) of north-western Mongolia.

\section{Diagnosis}

433 As for the type species.

434

435 SODOLEPIS LUCENS Karatajūtè-Talimaa \& Novitskaya, 1997 
436 (Figs. 3H-J, 6G-J, 8E)

4371997 Sodolepis lucens Karatajūtè-Talimaa \& Novitskaya, figs. 1-3, pl. XI.

4381998 Sodolepis lucens Karatajūtè-Talimaa, fig. 18.

439 Emended diagnosis

440 Mongolepidids with medium-sized scales (up to over $2 \mathrm{~mm}$ ) possessing crowns

441 composed of sutured odontocomplex rows, whose number does not increase with

442 scale size. Anterior crown platform of globular dentine elevated to the level of the

443 crown surface. Neck (horizontal) canals not formed at the lower portion of crown

444 odontodes.

445 Holotype

446 An isolated scale with accession number LGI M-1-091 deposited in collection LGI M-1

447 of the Lithuanian Geological Survey, Vilnius (Karatajūtè-Talimaa \& Novitskaya, 1997).

\section{Referred material}

449 More than a hundred isolated scales from the type locality (samples P-16/3 and ЦЦГЭ

450 N1009). Non-figured specimens examined for this study are stored in the Lapworth

451 Museum of Geology, University of Birmingham, UK.

\section{Remarks}

453 The gross morphology of Sodolepis scales (Fig. 3H-J) closely resembles that of

454 Teslepis, with the two genera demonstrating comparable histology. The latter,

455 however, are distinguished on the basis of differences in odontode size and crown 
456 vascularization. Sodolepis crowns possess fused odontocomplexes, composed of

457 odontodes that are on average three times as large of those of Teslepis, divided by

458 inter-odontocomplex spaces. This is due to a corresponding increase of odontode and

459 scale size in Sodolepis, leading to the formation of a relatively constant number of

460 odontocomplexes irrespective of crown dimensions. In Teslepis specimens, on the

461 other hand, odontode size remains consistent across all documented scale lengths.

462 As noted by Karatajūtè-Talimaa \& Novitskaya (1997), a system of horizontal

463 canals cannot be identified inside Sodolepis scale crowns (Fig. 8E)—an atypical

464 condition considering that the majority of mongolepid genera, including Teslepis,

465 develop some type of pulp canal openings on the lower crown surface.

467 Genus RONGOLEPIS Sansom, Aldridge \& Smith, 2000

468 Type and only species

469 Rongolepis cosmetica from the Telychian (Upper Llandovery) of south China, Lower

470 Member of the Xiushan Formation (Sansom, Aldridge \& Smith, 2000) and the

471 Telychian of Bachu County, Xinjiang, China (Lower member of the Yimugantawu

472 Formation; N-Z Wang, unpublished data).

473 Diagnosis

474 As for the type species. 
476 RONGOLEPIS COSMETICA Sansom, Aldridge \& Smith, 2000

477 (Figs. 3K-M, 6K, L)

4782000 Rongolepis cosmetica Sansom, Aldridge \& Smith, figs. 11, 12.

479 Emended diagnosis

480 Mongolepidid species with scale odontocomplex rows ornamented by narrow median

481 ridges, flanked anteriorly and laterally by conical secondary odontodes. Posterior

482 primary odontodes long and straight, having pitted by rows of foramina on their lower

483 crown face. Base tetragonal or oblong, displaced towards the scale anterior. Lower

484 base surface concave to flat with a central conical projection.

485 Holotype

486 An isolated scale (NIGP 130326) from the Xiushan Formation of south China

487 (Sansom, Aldridge \& Smith, 2000).

488 Referred material

489 Hundreds of specimens from the Xiushan Formation of Leijiatun (Shiqian county, 490 south China (sample Shiqian 14B), including type series material (NIGP 130319-

491 NIGP 130330) figured by Sansom, Aldridge \& Smith (2000). Non-figured specimens

492 stored in the Nanjing Institute of Geology and Palaeontology, Chinese Academy of

493 Sciences, Nanjing, China.

494 Remarks 
495 The uncertainty regarding the supergeneric position of Rongolepis in the original

496 description of the genus (Sansom, Aldridge \& Smith, 2000) has been attributed to a

497 suite of characteristics (scale morphology, posterior of the crown composed of

498 acellular lamellar bone and presence of crown odontodes) not known in the scales of

499 other vertebrates. The re-examination of Rongolepis cosmetica has enabled the

500 identification of a combination of features diagnostic for Mongolepidida. Of particular

501 importance in this regard is the nature of the tissue composing the flared posterior

502 extension of Rongolepis scales. Suggested to be formed of lamellar bone (Sansom et

503 al. 2000), this portion of the scale in fact demonstrates the lamellin-type architecture of

504 an inotropically and spheritically mineralized (for definitions of both see Ørvig, 1968

505 and Zylberberg et al. 1992) atubular tissue devoid of attachment fibres (Fig. 6K, L).

506 Moreover, the segmentation of the crown's posterior part observed in thin sections

507 (Fig. 6K, L; Sansom, Aldridge \& Smith, 2000, fig. 12e) is interpreted to be produced by

508 the contact surfaces of sutured odontodes. Both the anterior to posterior increase in

509 length of these elements and their arrangement in longitudinal rows over the posterior

510 half of the base are known features of mongolepid primary odontocomplexes. The

511 assignment of Rongolepis to Mongolepidida is thus dictated by the possession of its

512 scales of lamellin and polyodontocomplex growing crowns.

513

514 Family SHIQIANOLEPIDAE Sansom, Aldridge \& Smith 2000

515 Included Genera

516 Xinjiangichthys Wang et al., 1998 and Shiqianolepis Sansom, Aldridge \& Smith, 2000. 


\section{Emended diagnosis}

518 Mongolepids with scale bases composed of non-vascular, cellular bone tissue.

520 Genus SHIQIANOLEPIS Sansom, Aldridge \& Smith, 2000

521 Type and only species

522 Shiqianolepis hollandi Sansom, Aldridge \& Smith, 2000, from the Telychian Lower

523 Member of the Xiushan Formation (Leijiatun, Shiqian county, southern China).

524 Emended diagnosis

525 As for the type species.

526

527 SHIQIANOLEPIS HOLLANDI Sansom, Aldridge \& Smith, 2000

528 (Figs. 4A-C, 5N, 8F, 9B, E)

5292000 Shiqianolepis hollandi Sansom, Aldridge \& Smith, figs. 4-6.

530 Emended diagnosis

531 Shiqianolepids with trunk scale odontocomplexes separated posteriorly by deep inter-

532 odontocomplex spaces. A cluster of tightly sutured secondary odontodes formed

533 anteriorly of crown odontocomplexes. Crown surface ornamented by tuberculate 
534 ridges. Oblong asymmetrical head scales (up to $1 \mathrm{~mm}$ long) with irregularly-shaped

535 odontodes distributed peripherally around a medial ridge.

\section{Holotype}

537 An isolated trunk scale (NIGP 130294) from the Xiushan Formation of Leijiatun (Shiqian

538 County) south China (Sansom, Aldridge \& Smith, 2000).

\section{Referred material}

540 Hundreds of isolated scales and type series specimens (NIGP 130293-NIGP 130318)

541 figured by Sansom, Aldridge \& Smith (2000) from the Telychian Xiushan Formation

542 (sample Shiqian 14B) of Leijiatun (Shiqian county, south China). Non-figured material

543 stored in the Nanjing Institute of Geology and Palaeontology, Chinese Academy of

544 Sciences, Nanjing, China.

\section{Remarks}

546 Characteristic for Shiqianolepis scales is a distinct primordial odontode located at the

547 apex of the conical base. This odontode has been termed 'proto-scale' by Sansom,

548 Aldridge \& Smith (2000) and was identified as a diminutive element overlain by the

549 much larger odontodes deposited at later stages of crown ontogeny. Superpositional

550 growth, which results in odontodes not being exposed on the crown surface, is a

551 condition atypical for other mongolepids, also demonstrated to not be a feature of

552 Shiqianolepis scales. Upon re-examination of figured material and newly sectioned

553 specimens, the primordial odontode borders recognized in Sansom, Aldridge \& Smith

554 (2000, figs. $6 \mathrm{~b}, 7$ ) are now considered to constitute the margins of dentine depositional 
555 lamellae (Fig. $6 \mathrm{~N}$ ), as these are occasionally observed to be indented by more

556 peripherally formed calcospherites_evidencing a centripetal mode of dentine

557 histogenesis as opposed to stacking of primary odontodes. As identified here, the

558 primordial odontode in Shiqianolepis scales is overlapped only at its anterior end by

559 secondary odontodes, whilst most of its upper margin remains exposed on the crown

560 surface. Similarly to the rest of the odontocomplexes of Shiqianolepis trunk scales, the

561 one incepted by the 'proto-scale' also displays a gradual posterior increase of

562 odontode size.

563

564 Genus XINJIANGICHTHYS Wang, Zhang, Wang \& Zhu, 1998

565 Type and only species

566 Xinjiangichthys pluridentatus Wang, Zhang, Wang \& Zhu, 1998, from the Telychian

567 Yimugantawu Formation (north-western margin of the Tarim Basin, Xinjiang, PR

568 China).

569 Emended diagnosis

570 As for the type species.

571 Remarks

572 The placement of Xinjiangichthys inside Mongolepidida by Wang et al. (1998) was

573 justified on the grounds of similarities in crown morphology and odontode patterning

574 with Mongolian mongolepids (the only known mongolepid taxa at the time of its 
575 description), and this study advances that claim further by identifying a

576 polyodontocomplex crown structure in Xinjiangichthys scales.

The presence of atubular dentine in Xinjiangichthys scales, another of the

578 diagnostic characters of mongolepids (this study; Karatajūtè-Talimaa et al., 1990;

579 Sansom, Aldridge \& Smith, 2000), can be determined in thin-section (Fig. 6M) and

580 through X-ray microtomography (Fig 8G, H).

$581 \quad$ Furthermore, Wang et al.'s (1998) interpretation of Xinjiangichthys scale bases

582 as non-growing is rejected here by the recognition of a conical basal tissue that

583 supports, at its apex, the primordial odontode and further posteriorly the rest of the

584 scale's primary odontodes, similarly to the growing bases of Shiqianolepis and those

585 of mongolepids in large (Fig. 6M; Fig. 8H).

586

587 XINJIANGICHTHYS PLURIDENTATUS Wang, Zhang, Wang \& Zhu, 1998

588 (Figs. 4D-F, 6M, 8G-H)

5891998 Xinjiangichthys pluridentatus Wang, Zhang, Wang and Zhu, pl. 1, fig. a-d.

5901998 Xinjiangichthys tarimensis Wang, Zhang, Wang \& Zhu, pl. 1, fig. e-i.

591 v. 2000 Xinjiangichthys sp. Sansom, Aldridge and Smith, 236, fig. 8.

\section{Emended diagnosis}


593 Shiqianolepids with unornamented scale crowns composed of sutured odontocomplex

594 rows. Needle-like primary odontodes; erect, conical secondary odontodes.

\section{Holotype}

596 An isolated trunk scale (IVPP V11663.1) from the Yimugantawu Formation of Xinjiang

597 (Bachu county), China (Wang et al., 1998).

\section{Referred material}

599 Two specimens from the Telychian Xiushan Formation (Leijiatun, Shiqian county, 600 south China; sample Shiqian 14B), in addition to material figured (NIGP 130291, NIGP 601 130292) in Sansom, Aldridge \& Smith (2000), and five specimens (including IVPP V 602 X1, IVPP V X2) from the Yimugantawu Formation (Bachu county, Xinjiang, PR China).

603 Non-figured scales are stored in the Nanjing Institute of Geology and Palaeontology, 604 Chinese Academy of Sciences, Nanjing, China and the Institute of Vertebrate 605 Paleontology and Paleoanthropology, Chinese Academy of Sciences, Beijing, China.

\section{Remarks}

$607 X$. tarimensis and $X$. sp. are synonymised with $X$. pluridentatus based on the absence 608 of differentiating characteristics between the specimens attributed to the two species.

609 The arguments (equal-sized crown odontodes, scale neck and pitted sub-crown

610 surface) of Wang et al. (1998) for erecting $X$. tarimensis are considered not valid for

611 the following reasons. The large-diameter anterior odontodes of $X$. pluridentatus

612 specimens figured by Wang et al. (1998, pl. la, c) represent secondary odontodes not

613 developed in all scales of the species (specimens identified as $X$. tarimensis by Wang 
614 et al., 1998, pl. le-i), which is consistent with the condition documented in Mongolepis

615 (this study and Karatajūtè-Talimaa et al., 1990). The presence of secondary

616 odontodes also accounts for the lack of a distinct neck in the Xinjiangichthys scales

617 they develop, by occupying the sloped anterior surface of the base. The third

618 character considered diagnostic for $X$. tarimensis by Wang et al. (1998) are the

619 numerous foramina present on the lower crown surface of scales, which are also seen

620 (Figs. 4D, E, 8G-H) in Xinjiangichthys specimens with secondary odontodes.

622 Family incertae sedis

623 Genus SOLINALEPIS gen. nov.

624 Type and only species

625 Solinalepis levis gen. et sp. nov.

626 Derivation of name

627 From 'solinas' (tube, pipe in Greek), pertaining to the shape of the scale odontodes of 628 the species, and 'lepis', scale in Greek.

629 Diagnosis

630 As for the type species.

631 Remarks 
632 Characters relating to the dimensions of the scale base (its extent and thickness in

633 relation to those of the crown) unite Solinalepis gen. nov. (data from yet to be

634 published phylogenetic analysis by Andreev, Coates \& Sansom, unpublished; Fig. 2)

635 in a clade with members of Shiqianolepidae. Nevertheless, this type of morphological

636 data is not regarded informative at a supra-generic level and the genus is classified

637 outside the two recognized mongolepid families due to differences in scale base

638 histology (acellular bone lacking plywood-like organization of its mineralised matrix).

639 As a consequence, Solinalepis gen. nov. is treated as Mongolepidida incertae sedis.

640

641 SOLINALEPIS LEVIS sp. nov

642 (Figs. 5, 7, 8I-J, 9C)

6432001 '?Mongolepid scales' Sansom, Smith and Smith, p. 161, fig. 10.3g, h.

6442002 Unnamed chondrichthyan Donoghue and Sansom, p. 362, fig. 6.3.

6452009 Stem-chondrichthyan Sire, Donoghue and Vickaryous, p. 424, fig. 10c.

\section{Derivation of name}

647 From the Latin 'levis' (smooth), referring to the unornamented scale crown surface of 648 the species.

\section{Locality and horizon}


650 The type locality is the vicinity of the Harding Quarry, situated c. $1 \mathrm{~km}$ west of Cañon

651 City (Fremont County, Colorado, USA). All Solinalepis specimens come from

652 Sandbian strata (Mohawkian regional series, Phragmodus undatus conodont zone) of

653 the Harding Sandstone (samples H94-26 and H96-20).

654 Holotype

655 An isolated trunk scale BU5310 (Fig. 5E).

\section{Referred material}

657 Hundreds of isolated scales, including BU5307-BU5318, BU5345.

658 Non-figured specimens examined for this study are stored in the microvertebrate

659 research collection of the Lapworth Museum of Geology, University of Birmingham, 660 UK.

\section{Diagnosis}

662 Mongolepid species with trunk scales crowns composed of tubular odontodes

663 organized in sutured longitudinal odontocomplex rows. Acellular basal bone housing

664 an elaborate canal system that opens via foramina on the basal surface. Radially

665 arranged tuberculate to conical head-scale odontodes.

\section{Description}

\section{Morphology of head scales}

668 Polyodontode symmetrical or asymmetrical scales with height between 0.5 and 1.3

$669 \mathrm{~mm}$. These are represented by two main morphological variants, a compact, bulbous 
670 type (Fig. 5D) and tessera-like scales (Fig. 5A-C) of larger diameter. Both

671 morphotypes possess irregular crowns composed of radially ordered odontodes, and

672 do not clearly exhibit distinct anterior, posterior and lateral scale faces. The radiating

673 odontodes form rows (five to nine odontodes long), offset in a manner in which the

674 odontodes of each row oppose the inter-odontode contacts of neighbouring

675 odontocomplexes. Odontode height diminishes gradually towards the crown centre,

676 accompanied by an increase of coalescence between odontodes.

677 The scales exhibit a prominent central bulge, away from which the crown

678 surface slopes down to the scale margin. In crown view, the latter has a corrugated

679 outline that in certain specimens is accentuated by deep, peripherally expanding 680 grooves (Fig. 5A, B).

681

The scale base displays a granular, grooved surface and follows the outline of

682 the crown. At its centre the base attains maximal thickness (Fig. 7A), and gradually

683 decreases in height away from this point. The lower-base surface is predominantly

684 planar or can have a moderate central concavity, but never exhibits the convex

685 topology documented in trunk scale specimens.

Morphology of trunk scales

687 The length of these scales varies between $100-400 \mu \mathrm{m}$ and is always less (up to 688 three quarters) than their width. Specimens with crown lengths near or exceeding 200 $689 \mu \mathrm{m}$ demonstrate polygonal (Fig. 5E-G), often asymmetrical (Fig. 5F, G), outlines. The

690 anterior crown margin of these scales is typically wedge-shaped whilst their posterior

691 face is straight (Fig. 5I). In contrast, the crowns of antero-posteriorly short (100-200 
$692 \mu \mathrm{m}$ long) scales tend to be symmetrical, leaf-shaped structures (Fig. $5 \mathrm{~J}-\mathrm{L}$ ), rarely

693 demonstrating simple geometrical profiles in crown view.

$694 \quad$ Irrespective of crown morphology, the odontodes of trunk scales are organized

695 into closely packed antero-posteriorly aligned rows (Figs 5F-G, J, 9C). Adjacent rows

696 are displaced by approximately half an odontode diameter (c. $15 \mu \mathrm{m})$, resulting in an

697 offset between the odontodes of neighbouring odontocomplexes (Fig. 9C). The

698 odontodes themselves are cylindrical, tube-like elements with sigmoidal profiles that

699 taper to a point apically (Fig. 5J). Odontode length increases gradually towards the

700 scale's posterior end, where the crown can reach a height of c. $400 \mu \mathrm{m}$.

701 The crown/base transition is not marked by a neck-like constriction (Fig. 5E-L),

702 with the base never attaining more than a third of the overall scale height. The basal

703 surface is typically marked by deeply incised grooves (Fig. 5E-I) that give it a dimpled

704 appearance, characteristic also for the lower base surface. The latter has a

705 predominantly flat profile but can exhibit a central conical projection that is particularly

706 well developed in leaf-shaped specimens (Fig. 5L).

\section{Histology of head scales}

708 Due to diagenetic alteration of histologically examined scales, the microstructure of

709 crown odontodes is largely obscured. Nevertheless, wide odontode pulp canals are

710 evident in sectioned specimens (Fig. 7A), and these appear to end blindly inside the

711 crown. The upper base surface is perforated by a row of foramina (Fig. 5C, D) similar

712 to the ones documented in trunk scales. 
713 The main structural components of the basal bone matrix are tightly packed, parallel

714 crystalline mineralized fibres with horizontal orientation (Fig. 7A). These are crosscut

715 by apically converging fibre bundles (up to $15 \mu \mathrm{m}$ in diameter), which follow undulating

716 paths across the tissue.

\section{Histology of trunk scales}

718 Crown odontodes are structured out of atubular dentine (lamellin; Fig. 7B) that is

719 spherically mineralised in proximity of the pulp (spherite diameter 10-15 $\mu \mathrm{m}$ ).

720 Cylindrical, non-branching pulp cavities occupy the centre of odontodes and are

721 connected at their lower ends with the canal system of the base (Fig. 8I, J). The latter

722 is represented by vertical canals that bifurcate close to the crown-base junction, with

723 each pair of rami re-connecting deeper inside the base, resulting in the formation of a

724 series of vascular loops (Fig. 8I, J). Vertically oriented canals emerge from the looped

725 canal system and open on the lower base surface. The basal surface is similarly

726 marked by numerous foramina that are the exit points for the peripheral canals of the

727 base (Fig. $5 \mathrm{H})$.

728 The base is composed of acellular bone demonstrating the presence of $c .2 \mu \mathrm{m}$ thick

729 extrinsic crystalline mineralised fibres that propagate vertically through the tissue (Fig.

730 7B).

\section{Remarks}

732 The development of polyodontocomplex scale crowns formed from lamellin identify

733 Solinalepis levis gen. et sp. nov. scales as a mongolepid species. Moreover, the trunk 
734 scale odontocomplexes of Solinalepis gen. nov. exhibit the same progressive posterior

735 increase in odontode length documented in members of the Order.

736 Within Mongolepidida, the combination of a large odontocomplex number (>20)

737 and sutured odontodes is present only in the Telychian genus Xinjiangichthys.

738 Nevertheless, the two taxa are readily distinguished on the basis of base histology and

739 canal-opening distribution on the scale surface. In addition to that, Solinalepis gen.

740 nov. is one of only two described mongolepid genera (the other being Shiqianolepis)

741 known to develop with squamation clearly differentiated into distinct trunk (exhibiting

742 recognizable anterior and posterior faces) and head morphotypes (irregular-shaped

743 elements) - a condition that is consistent with that recorded in a number of

744 heterosquamous Lower Palaeozoic gnathostomes known from articulated specimens

745 (e.g. Climatius reticulatus Miles, 1973, Obtusacanthus corroconius Hanke \& Wilson,

746 2004, Gladiobranchus probaton Hanke \& Davis, 2008 and Ptomacanthus anglicus

747 Miles, 1973; Brazeau, 2012).

748

749 DISCUSSION

750 Crown morphogenesis of mongolepid scales

751 Shiqianolepis hollandi is recognized as a key taxon for determining the mode of scale

752 crown development in mongolepids, following the identification by Sansom, Aldridge \&

753 Smith (2000) of 'proto-scale' (early-development phase) specimens of the species

754 (Sansom, Aldridge \& Smith, 2000, fig. 4u, w). The size (half of that of 'mature' trunk 
755 scales) and the small number of crown odontodes (exhibiting only the earliest formed

756 odontodes of incipient primary odontocomplexes) of these scales implies that in

757 Shiqianolepis scale ontogenesis involves crown enlargement through sequential

758 addition of odontodes. Significantly, this style of crown architecture (primary

759 odontocomplex rows originating at the most elevated point of the base and

760 characterized by a posterior increase in size of their constituent odontodes) is

761 developed in all members of the Mongolepidida (Figs. 6A, F, I, K, M, N, 9) and is

762 evidence that the mongolepids share a cyclomorial pattern of scale ontogenesis.

763 Data from developmental studies on extant neoselachians indicate that their

764 scales cannot serve as model systems for determining the mechanism of

765 morphogenesis of the compound mongolepid scale crowns, as the former have been

766 shown to be simple monodontode elements produced by a single epithelio-

767 ectomesenchymal primordium (Schmidt \& Keil, 1971; Reif, 1980, Miyake et al., 1999;

768 Sire \& Huysseune, 2003; Johanson, Smith \& Joss, 2007; Johanson et al., 2008).

769 Examinations of multiple odontode generation in osteichthyan scales (Kerr, 1952;

770 Smith, Hobdell \& Miller, 1972; Smith, 1979; Sire \& Huysseune, 1996), though, provide

771 insight into the timing of deposition of odontode aggregations associated with a dermal

772 bone support tissue. They reveal phases of odontode generation that result in an

773 increase of odontode number throughout scale ontogeny.

The proposed scale growth mechanism in Mongolepidida is further

775 substantiated by evidence from the Palaeozoic record of the Chondrichthyes. The

776 scale crown structure of certain euchondrichthyan taxa described from articulated

777 specimens (e.g. Diplodoselache woodi Dick, 1981, Tamiobatis vetustus Williams, 
7781998 and Orodus greggi Zangerl, 1968), conform closely to the odontode patterning of

779 mongolepid scales. Diplodeselache trunk scales were noted by Dick (1981) to closely

780 resemble those of Orodus and to be similarly characterized by cyclomorial growth.

781 Previous work (Reif, 1978) on the morphogenesis of the chondrichthyan

782 integumentary skeleton also recognized sequential crown elongation through regular

783 addition of odontodes as the mechanism of scale development in Orodus. This pattern

784 of crown formation is also typical for scales with a Ctenacanthus costellatus type of

785 morphogenesis (defined by Reif, 1978 and equivalent to the Ctenacanthus B3

786 morphogenetic type of Karatajūtè-Talimaa, 1992) to which Tamiobatis scales have

787 been attributed (Williams, 1998).

788 Mongolepid scale crown histology

789 The emergence of skeletal mineralisation in vertebrates (Donoghue \& Sansom, 2002;

790 Donoghue, Sansom \& Downs, 2006) coincides with the origin of atubular dentine-like

791 tissues that compose the basal bodies of certain conodont genera (Sansom, 1996;

792 Smith, Sansom \& Smith, 1996; Donoghue, 1998; Dong, Donoghue \& Repetski, 2005).

793 Conodont atubular 'dentines' frequently exhibit (Sansom 1996, fig. 2e-h; Donoghue,

794 1998, fig. 5a-c; Dong, Donoghue \& Repetski, 2005, pl. 1, figs 3-9) peripheral lamellar

795 fabric, substituted internally by spheritically mineralised matrix, making them

796 structurally (but not phylogenetically) comparable with the architecture of mongolepid

797 lamellin (Fig. 6C, G). The conodont tissues have recently been hypothesized to have

798 arisen in a stepwise manner in the oropharyngeal skeleton of the Paraconodonta and

799 Euconodonta (Murdock et al., 2013), whilst separately, within the Total Group 
800 Gnathostomata the known occurrence of atubular dentines outside the Mongolepidida

801 is limited to the scale odontodes of the pteraspidomorph Tesakoviaspis concentrica

802 (Karatajūtè-Talimaa \& Smith, 2004) and the fin spine ornament of sinacanthid

803 gnathostomes (Sansom, Aldridge \& Smith, 2000; Sansom, Wang \& Smith, 2005).

804 An important aspect of the atubular nature of lamellin is that it provides circumstantial

805 evidence for the involvement of atypical (from a modern perspective) odontoblasts in

806 the generation of the tissue. During dentinogenesis mature odontoblasts commonly

807 extend long cellular processes into the mineralised phase, which remain contained

808 inside tubular spaces after formation of the tissue is complete (Linde, 1989; Linde \&

809 Lundgren, 1995; Yoshiba et al., 2002; Magloire et al., 2004, 2009). The inability of

810 secretory odontoblasts to form dentinal tubules is taken to suggest that such cells

811 either did not embed their processes within the dentine matrix at any depth or lacked

812 processes altogether. Atypical odontoblasts devoid of large cytoplasmic projections

813 have been reported in the tooth germs of the Recent sting ray Dasyatis akajei

814 (Sasagawa, 1995), but these are found to co-exist with unipolar odontoblasts,

815 characterized by well-developed processes. The apical portions of odontoblasts and

816 their processes have been implicated as ion channel-rich sites capable of being

817 activated by environmental stimuli via tubular fluid movement, and are presumably

818 involved in transmitting sensory input to pulp nerve endings (Okumura et al., 2005;

819 Allard et al., 2006; Magloire et al., 2009). This raises the possibility that mongolepid

820 scale pulps had limited ability to transduce sensory input compared with an

821 odontoblast population that forms tubular network inside a mineralised dentine matrix.

\section{Histology of mongolepid scale bases}


823 This and previous studies (Karatajūtè-Talimaa et al., 1990; Karatajūtè-Talimaa 1995;

824 Karatajūtè-Talimaa \& Novitskaya, 1992, 1997; Sansom, Aldridge \& Smith, 2000)

825 identify mongolepid scale odontodes to be supported by a common base composed of

826 lamellar bone (Fig. 6A, F, H, I, K, M, N, 7). The basal tissue of Mongolepis and

827 Sodolepis scales has been interpreted as acellular bone (Karatajūtè-Talimaa et al.,

828 1990; Karatajūtè-Talimaa \& Novitskaya, 1997), with this study also recognizing the

829 absence of osteocyte lacunae in the bases of Teslepis (contra Karatajūtè-Talimaa \&

830 Novitskaya, 1992), Rongolepis (in agreement with Sansom, Aldridge \& Smith, 2000)

831 and Solinalepis gen. nov.--restricting the occurrence of cellular bone inside

832 Mongolepidida to the genera Xinjiangichthys and Shiqianolepis (this study and

833 Sansom, Aldridge \& Smith, 2000).

834 A cross-ply layering of crystalline fibres is recognized as the predominant type

835 of basal bone texture of mongolepid scales, being documented in the four genera of

836 the Family Mongolepididae. This architecture of the mineralised matrix matches

837 closely the organization of the collagen fibres in the deep dermis (stratum compactum)

838 of extant neoselachians (Motta 1977; Miyake et al., 1999; Sire \& Huysseune, 2003)

839 and osteichthyans (Kerr, 1952, 1955; Sire, 1993; Gemballa \& Bartsch, 2002) and is

840 suggested to be indicative of dermal bone histogenesis achieved through

841 mineralisation of the a largely unmodified fibrous scaffold of the stratum compactum-

842 a process referred to as metaplastic ossification (Sire, 1993; Sire, Donoghue \&

843 Vickaryous, 2009). Consequently, the observed absence of cross-ply layering in the

844 cellular bone of mongolepid scale bases (in Xinjiangichthys, Shiqianolepis and

845 Solinalepis gen. nov.) could be interpreted to result from remodeling of the original 
846 fibrous framework of stratum compactum prior to tissue mineralisation (a process

847 described by Sire 1993 in the scales of the armoured catfish Corydoras arcuatus).

848 The data above allow the identification of the site of basal bone formation of

849 mongolepid scales within the deep tiers of the corium, with the tissue being

850 considered to periodically increase in size due to the growth increments documented

851 in sectioned specimens. These depositional phases reveal a common pattern of

852 generation of mongolepid scale bases, wherein each newly laid down lamella covers

853 the lower surface of the previously deposited one. The geometry of the lamellae

854 shows little change, implying retention of a fairly consistent base shape throughout

855 scale ontogeny. Such a pattern of base morphogenesis is not unique to the

856 Mongolepidida, but appears to be the prevalent mode of bone tissue growth in the

857 scales of jawed gnathostomes, being demonstrated in 'placoderms' (Burrow \& Turner,

858 1998, 1999), 'acanthodians' (Denison, 1979), early osteichthyans (Gross, 1968;

859 Schultze, 1968) and early chondrichthyans (Karatajūtè-Talimaa, 1973; Mader, 1986;

860 Wang, 1993).

\section{Canal system of mongolepid scales}

862 Previously, the internal canal system architecture of mongolepid scales had been

863 investigated in detail only in Mongolepis, Teslepis and Sodolepis through oil

864 immersion studies and thin section work (Karatajūtè-Talimaa et al., 1990; Karatajūtè-

865 Talimaa \& Novitskaya, 1992, 1997). The employment of X-ray microtomography

866 extended to these observations by enabling visualization of the three-dimensional

867 structure of scale cavity spaces in the examined genera with greater accuracy. 
868 In Mongolepis, Teslepis, Sodolepis and Solinalepis gen. nov. the lower ends of

869 odontode pulp cavities are continuous with the canal system of the base. Comparable

870 vascularization is developed in the Upper Ordovician chondrichthyan scale species

871 Tezakia hardingensis from North America (Andreev et al. 2015). The lower base

872 surface of this taxon has been demonstrated to exhibit rows of foramina (Sansom,

873 Smith \& Smith, 1996, fig. 2a) that are similar to the basal canal openings of

874 mongolepids. Likewise, the central canal of the basal bone tissue is continuous with

875 the odontode pulp in the Silurian scale genera Elegestolepis (Karatajūtè-Talimaa,

876 1973; Andreev et al., in press) and Kannathalepis (Märss \& Gagnier, 2001), which

877 are the earliest recorded monodontode scale taxa attributed to the Chondrichthyes

878 (Andreev et al., in press). This condition is also identified in the monodontode scales

879 of various Upper Palaeozoic chondrichthyans (e.g. Janassa Ørvig, 1966; Malzahn,

880 1968, Ornithoprion Zangerl, 1966 and Hopleacanthus Schaumberg, 1982), Mesozoic

881 hybodonts (Reif, 1978) and extant neoselachians (Reif, 1980; Miyake et al., 1999;

882 Johanson et al., 2008).

883

Xinjiangichthys, Shiqianolepis and Rongolepis differ from the other mongolepid

884 genera in having their entire scale canal system confined to the crown, with the lower

885 ends of odontode pulps opening at the crown surface in proximity of the base. The

886 posterior peripheral odontodes of these three genera display additional cavities that

887 are detected as foramina on the lower crown face. A similarly pitted lower crown

888 surface has also been identified in poracanthodid 'acanthodians' (Gross 1956;

889 Valiukevičius, 1992; Burrow, 2003), the putative stem chondrichthyan Seretolepis

890 (Hanke \& Wilson, 2010; Martínez-Pérez et al., 2010), and in ctenacanthiform scales 
891 (e.g. Tamiobatis vetustus Williams, 1998 and Ctenacanthus costellatus Reif, 1978). In

892 the scales of Poracanthodes these openings represent the posterior exit points of a

893 complex canal network that is absent from mongolepid scale crowns.

Studies on the squamation of jawed gnathostomes reveal the lack of basal

895 tissue vascularisation to be a common feature of many 'acanthodians' (Denison, 1979;

896 Karatajūtè-Talimaa \& Smith, 2003; Valiukevičius, 2003; Valiukevičius \& Burrow, 2005)

897 and euchondrichthyans such as Protacrodus (Gross, 1973), Orodus (Zangerl, 1968)

898 and Holmesella (Ørvig, 1966), including some of the earliest known post-Silurian

899 putative chondrichthyan taxa (e.g. Iberolepis and Lunalepis Mader, 1986;

900 Nogueralepis Wang, 1993; Gladbachus Burrow \& Turner, 2013).

901 Despite the observed differences in canal architecture, all mongolepid genera

902 with the exception of Sodolepis develop canal openings exposed on the scale surface

903 in the region the crown-base interface. These foramina represent the termini of canals

904 that are positionally equivalent to, and likely homologues of, the neck canals of

905 euselachians (sensu Reif, 1978). In Mongolepis and Teslepis this connection is

906 established via one pair of short canals (the 'horizontal canals' of Karatajūtè-Talimaa

907 et al., 1990, Karatajūtè-Talimaa \& Novitskaya, 1992 and Karatajūtè-Talimaa, 1998)

908 that emerge from the lower end of each pulp. The data presented here indicate that

909 the horizontal canal system of these two genera is housed inside the scale crown,

910 contrary to previous depictions of the feature at the crown-base junction (Karatajūtè-

911 Talimaa, 1995, 1998). In contrast, the lower ends of odontode pulp canals of North

912 American and Chinese mongolepids do not branch out, and either continue inside the

913 base without being exposed on the crown surface (Solinalepis gen. nov.) or open 
914 directly onto it (Shiqianolepis and Rongolepis). These features point to notable

915 variation in the vascularization of mongolepid species, which are otherwise remarkably

916 consistent in the development of their scales. However, it is unclear if these

917 differences had any influence on the rates of growth and regeneration of the

918 integumentary skeleton.

\section{Systematic position of the Mongolepidida}

920 Recent phylogenetic investigations of Palaeozoic gnathostomes use only a small

921 subset of generalized scale characters (Brazeau, 2009; Davis, Finarelli \& Coates,

922 2012; Zhu et al., 2013; Giles, Friedman \& Brazeau, 2015), and this is likewise true for

923 tree reconstructions of the total group Chondrichthyes, where scale data tend to be

924 minor components of employed character matrices (Lund \& Grogan, 1997; Coates \&

925 Sequeira, 2001; Grogan \& Lund, 2008; Grogan, Lund \& Greenfest-Allen, 2012).

926 Chondrichthyan clades instead have often been erected upon tooth characters

927 (Zangerl, 1981; Stahl, 1999; Ginter, Hampe \& Duffin, 2010), leaving the position of

928 lower Palaeozoic shark-like scale taxa still unresolved in phylogenetic hypotheses for

929 the Chondrichthyes.

930 The coherence of the Mongolepidida is reaffirmed here on the basis of an

931 amended character set, which diagnoses the Order by the unique combination of

932 scale growth, polyodontocomplex scale crowns and development of lamellin. The

933 placement of mongolepids within Chondrichthyes, on the other hand, has been

934 questioned in the past on the basis of their atubular dentine (lamellin) crowns and the

935 presence of a horizontal canal system (Karatajūtè-Talimaa \& Novitskaya, 1992). This 
936 study suggests that the horizontal canals of Mongolepis and Tes/epis are equivalent to

937 euselachian neck canals, whilst revealing similar canal spaces in the crown odontodes

938 of Chinese mongolepids. However, neck canals are likewise also known in the scales

939 of 'placoderms' (Burrow \& Turner, 1998) and basal Palaeozoic osteichthyans (Gross,

940 1953, 1968), and might not by a chondrichthyan apomorphy. Also, scale dentine

941 histology appears to vary greatly within the total group Chondrichthyes (e.g. distinct

942 dentine types are developed in Elegestolepis Karatajūtè-Talimaa, 1973, Seretolepis

943 Hanke and Wilson 2010, Orodus Zangerl, 1968 and Hybodus Reif, 1978), which

944 makes it a poor diagnostic character at a supra-ordinal level. By the same token,

945 although atubular dentine occurs in the Mongolepidida, it is also formed in the dermal

946 skeleton of some pteraspidomorph agnathans (Karatajūtè-Talimaa \& Smith, 2004) and

947 fin spines that may be of chondrichthyan origin (Zhu, 1998; Sansom et al., 2005), and

948 therefore is uninformative with respect to the relationships of the Order. The

949 systematic affinities of Mongolepidida are determined instead by a unique combination

950 of scale attributes that are shared with other Palaeozoic chondrichthyan lineages.

951 Reference is made here to the Ctenacanthus-type squamation of certain

952 xenacanthiform (Diplodoselache Dick, 1981), orodontiform (Orodus Zangerl, 1968)

953 and cladodontomorph (e.g. Cladolepis Burrow, Turner \& Wang, 2000 and

954 Cladoselache Dean, 1909; P. Andreev pers. obs.) chondrichthyans, characterized by

955 the development of symmetrical trunk scales with multiple crown odontocomplexes

956 that lack cancellous bone, enamel and hard tissue resorption. 


\section{CONCLUSIONS}

959 The present revision of Mongolepidida established the Order as a natural group of

960 early chondrichthyans characterized by polyodontocomplex growing scales with

961 Ctenacanthus-like crown architecture. However, in agreement with Karatajūtè-Talimaa

962 (1992), the scales of mongolepids are recognized to exhibit a distinct, Mongolepis,

963 type of morphogenesis, on account of their lamellin composed crowns.

964 The description of the mongolepid genus Solinalepis gen. nov. from the

965 Sandbian of North America, pushes back the first appearance of the Mongolepidida by

$96620 \mathrm{My}$ and places the origin of the Chondrichthyes in the Ordovician. Together with

967 reports of other shark-like scale taxa from the Ordovician (Sansom, Smith \& Smith,

968 1996; Sansom, Smith \& Smith, 2001; Sansom et al., 2012) and the Silurian

969 (Karatajūtè-Talimaa, 1973; Karatajūtè-Talimaa \& Predtechenskyj, 1995; Sennikov et

970 al., 2015), this lends further support of an early diversification of putative

971 chondrichthyans (proposed by Karatajūtè-Talimaa, 1992) that preceded a major

972 radiation of nektonic faunas (Klug et al., 2010), coincident with the first known

973 appearance of chondrichthyan teeth and articulated skeletal remains in the Lower

974 Devonian.

975

976

977 
978

979

980

981

982

983

984

\section{ACKNOWLEDGEMENTS}

986 Solinalepis material was collected from the Harding Sandstone during fieldwork

987 undertaken as part of research conducted by M. Paul Smith (Oxford) and Moya Smith

988 (King's College, London), and we are grateful to both for discussions on the nature of

989 these specimens over the years, whilst specimens of Shiqianolepis were made

990 available for study by the late Richard J. Aldridge (Leicester). Rachel Sammons and

991 Michael Sandholzer provided technical assistance during SEM and micro-CT imaging

992 of mongolepid scales at the School of Dentistry, University of Birmingham. We are

993 also grateful to Kate Trinajstic, Živilè Žigaitė and one anonymous reviewer for their

994 constructive and helpful comments on the originally submitted manuscript. 
995 The authors would like to highlight the contribution of the deceased N-Z Wang to this

996 study, who initially examined and provided the Chinese mongolepid material described

997 here.

998

999

1000

1001

1002

1003

1004

1005 REFERENCES

1006 Allard B, Magloire H, Couble ML, Maurin JC, Bleicher F. 2006. Voltage-gated

1007 Sodium Channels Confer Excitability to Human Odontoblasts. Journal of Biological

1008 Chemistry 281:29002-29010.

1009 Andreev PS, Coates MI, Shelton RM, Cooper PR, Smith MP, Sansom IJ. 2015.

1010 Upper Ordovician chondrichthyan-like scales from North America. Palaeontology

1011 58:691-704.

1012 Andreev PS, Coates MI, Karatajūtè-Talimaa V, Shelton RM, Cooper PR, Sansom IJ.

1013 in press. Elegestolepis and its kin, the earliest monodontode chondrichthyans. Journal 
1014 of Vertebrate Paleontology.

1015 Bolshakova L, Ulitina L. 1985. Stromatoporates and biostratigraphy of the Lower

1016 Paleozoic in Mongolia. Transsec. Joint Soviet-Mongolian paleontological expedition

$1017 \quad 27: 1-94$.

1018 Botella H, Donoghue P, Martínez-Pérez C. 2009. Enameloid microstructure in the

1019 oldest known chondrichthyan teeth. Acta Zoologica 90:103-108.

1020 Brazeau MD. 2009. The braincase and jaws of a Devonian 'acanthodian' and modern

1021 gnathostome origins. Nature 457:305-308.

1022 Brazeau MD. 2012. A revision of the anatomy of the Early Devonian jawed vertebrate

1023 Ptomacanthus anglicus Miles. Palaeontology 55:355-367.

1024 Brazeau MD, Friedman M. 2015. The origin and early phylogenetic history of jawed

1025 vertebrates. Nature 520:490-497.

1026 Burrow CJ. 2003. Redescription of the gnathostome fish fauna from the mid-

1027 Palaeozoic Silverband Formation, the Grampians, Victoria. Alcheringa 27:37-49.

1028 Burrow CJ, Turner S. 1998. Devonian placoderm scales from Australia. Journal of

1029 Vertebrate Paleontology 18:677-695.

1030 Burrow CJ, Turner S. 1999. A review of placoderm scales, and their significance in

1031 placoderm phylogeny. Journal of Vertebrate Paleontology 19:204-219.

1032 Burrow CJ, Turner S. 2013. Scale structure of putative chondrichthyan Gladbachus

1033 adentatus Heidtke \& Krätschmer, 2001 from the Middle Devonian Rheinisches

1034 Schiefergebirge, Germany. Historical Biology 25:385-390.

1035 Burrow CJ, Turner S, Wang S. 2000. Devonian microvertebrates from Longmenshan,

1036 China: Taxonomic assesssment. In: Blieck A, and Turner S, eds. Palaeozoic vertebrate 
1037 biochronology and global marine/non-marine correlation: final report of IGCP 328 (1991-

1038 1996). Frankfurt a. M.: Courier Forschungsinstitut Senckenberg, 391-451.

1039 Coates M, Sequeira S. 2001. A new stethacanthid chondrichthyan from the Lower

1040 Carboniferous of Bearsden, Scotland. Journal of Vertebrate Paleontology 21:438-459.

1041 Davis SP, Finarelli JA, Coates MI. 2012. Acanthodes and shark-like conditions in the

1042 last common ancestor of modern gnathostomes. Nature 486:247-250.

1043 Dean B. 1909. Studies on fossil fishes (sharks, chimaeroids and arthrodires). Memoirs

1044 of the American Museum of Natural History 9:211-248.

1045 Denison RH. 1979. Acanthodii. Stuttgart, New York: Gustav Fischer Verlag.

1046 Dick JR. 1981. Diplodoselache woodi gen. et sp. nov., an early Carboniferous shark

1047 from the Midland Valley of Scotland. Transactions of the Royal Society of Edinburgh:

1048 Earth Sciences 72:99-113.

1049 Dong XIP, Donoghue PCJ, Repetski JE. 2005. Basal tissue structure in the earliest

1050 euconodonts: Testing hypotheses of developmental plasticity in euconodont phylogeny.

1051 Palaeontology 48:411-421.

1052 Donoghue PCJ. 1998. Growth and patterning in the conodont skeleton. Philosophical

1053 Transactions of the Royal Society B: Biological Sciences 353:633-666.

1054 Donoghue PCJ, Sansom IJ. 2002. Origin and early evolution of vertebrate

1055 skeletonization. Microscopy research and technique 59:352-372.

1056 Donoghue PCJ, Sansom IJ, Downs JP. 2006. Early evolution of vertebrate skeletal

1057 tissues and cellular interactions, and the canalization of skeletal development. Journal

1058 of Experimental Zoology Part B: Molecular and Developmental Evolution 306:278-294.

1059 Downs JP, and Donoghue PC. 2009. Skeletal histology of Bothriolepis canadensis 
1060 (Placodermi, Antiarchi) and evolution of the skeleton at the origin of jawed vertebrates.

1061 Journal of Morphology 270:1364-1380.

1062 Gemballa S, Bartsch P. 2002. Architecture of the integument in lower teleostomes:

1063 Functional morphology and evolutionary implications. Journal of Morphology 253:290_

1064309.

1065 Giles S, Friedman M, and Brazeau MD. 2015. Osteichthyan-like cranial conditions in

1066 an Early Devonian stem gnathostome. Nature 520:82-85.

1067 Ginter M, Hampe O, Duffin CJ. 2010. Chondrichthyes: Paleozoic Elasmobranchii:

1068 Teeth. Munich: Verlag Dr. Friendrich Pfeil.

1069 Goloboff PA, Farris JS, and Nixon KC. 2008. TNT, a free program for phylogenetic

1070 analysis. Cladistics 24:774-786.

1071 Grogan ED, Lund R. 2008. A basal elasmobranch, Thrinacoselache gracia n. gen and

1072 sp., (Thrinacodontidae, new family) from the Bear Gulch Limestone, Serpukhovian of

1073 Montana, USA. Journal of Vertebrate Paleontology 28:970-988.

1074 Grogan ED, Lund R, Greenfest-Allen E. 2012. The origin and relationships of early

1075 chondrichthyans. In: Carrier JC, Musick J. A., Heithaus M. R., ed. Biology of sharks and

1076 their relatives. Boca Raton, FL: Taylor \& Francis Inc, 3-27.

1077 Gross W. 1953. Devonische Palaeonisciden-Reste in Mittel-und Osteuropa.

1078 Paläontologische Zeitschrift 27:85-112.

1079 Gross W. 1956. Über Crossopterygier und Dipnoer aus dem baltischen Oberdevon im

1080 Zusammenhang einer vergleichenden Untersuchung des Porenkanalsystems

1081 paläozoischer Agnathen und Fische. Kungliga Svenska vetenskapsakademiens

1082 handlingar 5:1-140. 
1083 Gross W. 1968. Fragliche Actinopterygier-Schuppen aus dem Silur Gotlands. Lethaia 1084 1:184-218.

1085 Gross W. 1973. Kleinschuppen, Flossenstacheln und Zähne von Fischen aus

1086 europäischen und nordamerikanischen Bonebeds des Devons. Palaeontographica

1087 Abteilung A 142:51-155.

1088 Hanke GF, Davis SP. 2008. Redescription of the acanthodian Gladiobranchus probaton

1089 Bernacsek \& Dineley, 1977, and comments on diplacanthid relationships. Geodiversitas

$1090 \quad 30: 303-330$.

1091 Hanke GF, Wilson MVH. 2004. New teleostome fishes and acanthodian systematics.

1092 In: Arratia G, Wilson, M. V. H. \& R. Cloutier ed. Recent Advances in the Origin and

1093 Early Radiation of Vertebrates. Munich: Verlag Dr. Friedrich Pfeil, 189-216.

1094 Hanke GF, Wilson MVH. 2010. The putative stem-group chondrichthyans

1095 Kathemacanthus and Seretolepis from the Lower Devonian MOTH locality, Mackenzie 1096 Mountains, Canada. In: D. K. Elliott JGM, X. Yu \& D. Miao, ed. Morphology, phylogeny

1097 and paleobiogeography of fossil fishes. Munich: Verlag Dr. Friedrich Pfiel, 159-182.

1098 Johanson Z, Smith MM, Joss JMP. 2007. Early scale development in Heterodontus

1099 (Heterodontiformes; Chondrichthyes): a novel chondrichthyan scale pattern. Acta

1100 Zoologica 88:249-256.

1101 Johanson Z, Tanaka M, Chaplin N, Smith M. 2008. Early Palaeozoic dentine and

1102 patterned scales in the embryonic catshark tail. Biology letters 4:87-90.

1103 Karatajūtè-Talimaa VN. 1973. Elegestolepis grossi gen. et sp. nov., ein neuer Typ der

1104 Placoidschuppe aus dem Oberen Silur der Tuwa. Palaeontographica Abt A 143:35-50.

1105 Karatajūtè-Talimaa VN. 1992. The early stages of the dermal skeleton formation in 
1106 chondrichthyans. In: Mark-Kurik E, ed. Fossil fishes as living animals. Tallinn: Institute

1107 of Geology, 223-231.

1108 Karatajūtė-Talimaa VN. 1995. The Mongolepidida: scale structure and systematic

1109 position. Geobios 19:35-37.

1110 Karatajūtè-Talimaa VN. 1998. Determination methods for the exoskeletal remains of

1111 early vertebrates. Mitteilungen ausdem Museum für Naturkunde in Berlin,

1112 Geowissenschaftliche Reihe 1:21-51.

1113 Karatajūtè-Talimaa VN, Novitskaya L. 1992. Teslepis-a new representative of

1114 mongolepid elasmobranchs from the Lower Silurian of Mongolia. Paleontologicheskii

1115 Zhurnal 4:36-46.

1116 Karatajūtè-Talimaa VN, Novitskaya L. 1997. Sodolepis-a new representative of

1117 Mongolepidida (Chondrichthyes?) from the Lower Silurian of Mongolia.

1118 Paleontologicheskii Zhurnal 5:96-103.

1119 Karatajūtè-Talimaa VN, Novitskaya L, Rozman KS, Sodov Z. 1990. Mongolepis-a

1120 new lower Silurian genus of elasmobranchs from Mongolia. Paleontologicheskii Zhurnal

$1121 \quad \mathbf{1}: 76-86$.

1122 Karatajūtè-Talimaa V, Predtechenskyj N. 1995. The distribution of the vertebrates in

1123 the Late Ordovician and Early Silurian palaeobasins of the Siberian Platform. Bulletin du

1124 Muséum National d'Histoire Naturelle 17:39-55.

1125 Karatajūtè-Talimaa VN, Smith MM. 2003. Early acanthodians from the Lower Silurian

1126 of Asia. Transactions of the Royal Society of Edinburgh: Earth Sciences 93:277-299.

1127 Karatajūtè-Talimaa VN, Smith MM. 2004. Tesakoviaspis concentrica: microskeletal

1128 remains of a new order of vertebrate from the Upper Ordovician and Lower Silurian of 
1129 Siberia. In: G. Arratia MVHWRC, ed. Recent Advances in the Origin and Early Radiation

1130 of Vertebrates. Munich, Germany: Verlag Dr. Friedrich Pfeil, 53-64.

1131 Kerr T. 1952. The scales of primitive living actinopterygians. Proceedings of the

1132 Zoological Society of London 122:55-78.

1133 Kerr T. 1955. The scales of modern lungfish. Proceedings of the Zoological Society of

1134 London 125:335-345.

1135 Klug C, Kroeger B, Kiessling W, Mullins GL, Servais T, Frýda J, Korn D, Turner S.

1136 2010. The Devonian nekton revolution. Lethaia 43:465-477.

1137 Linde A. 1989. Dentin matrix proteins: composition and possible functions in

1138 calcification. The Anatomical Record 224:154-166.

1139 Linde A, Lundgren T. 1995. From serum to the mineral phase. The role of the

1140 odontoblast in calcium transport and mineral formation. International Journal of

1141 Developmental Biology 39:213-213.

1142 Lund R, Grogan ED. 1997. Relationships of the Chimaeriformes and the basal

1143 radiation of the Chondrichthyes. Reviews in Fish Biology and Fisheries 7:65-123.

1144 Mader H. 1986. Schuppen und Zähne von Acanthodiern und Elasmobranchiern aus

1145 dem Unter-Devon Spaniens (Pisces). Göttingen: Geologischen Institute der Georg-

1146 August-Universität Göttingen.

1147 Magloire H, Couble ML, Romeas A, Bleicher F. 2004. Odontoblast primary cilia: facts

1148 and hypotheses. Cell biology international 28:93-99.

1149 Magloire H, Couble ML, Thivichon-Prince B, Maurin JC, Bleicher F. 2009.

1150 Odontoblast: a mechano-sensory cell. Journal of Experimental Zoology Part B:

1151 Molecular and Developmental Evolution 312:416-424. 
1152 Maisey J, Miller R, Turner S. 2009. The braincase of the chondrichthyan Doliodus from

1153 the Lower Devonian Campbellton formation of New Brunswick, Canada. Acta Zoologica

1154 90:109-122.

1155 Malzahn E. 1968. Über neue Funde von Janassa bituminosa (Schloth.) im

1156 niederrheinischen Zechstein. Geologisches Jahrbuch 85:67-96.

1157 Märss T, Gagnier PY. 2001. A new chondrichthyan from the Wenlock, Lower Silurian,

1158 of Baillie-Hamilton Island, the Canadian Arctic. Journal of Vertebrate Paleontology

$1159 \quad 21: 693-701$.

1160 Martínez-Pèrez C, Dupret V, Manzanares E, Botella H. 2010. New data on the Lower

1161 Devonian chondrichthyan fauna from Celtiberia (Spain). Journal of Vertebrate

1162 Paleontology 30:1622-1627.

1163 Miles RS. 1973. Articulated acanthodian fishes from the Old Red Sandstone of

1164 England, with a review of the structure and evolution of the acanthodian shoulder-girdle.

1165 Bulletin of the British Museum (Natural History) 24:111-213.

1166 Miller RF, Cloutier R, Turner S. 2003. The oldest articulated chondrichthyan from the

1167 Early Devonian period. Nature 425:501-504.

1168 Miyake T, Vaglia JL, Taylor LH, Hall BK. 1999. Development of dermal denticles in

1169 skates (Chondrichthyes, Batoidea): patterning and cellular differentiation. Journal of

1170 Morphology 241:61-81.

1171 Motta P. 1977. Anatomy and functional morphology of dermal collagen fibers in sharks.

1172 Copeia:454-464.

1173 Murdock DJ, Dong X-P, Repetski JE, Marone F, Stampanoni M, Donoghue PC.

1174 2013. The origin of conodonts and of vertebrate mineralized skeletons. Nature 502:546- 
1175549.

1176 Okumura R, Shima K, Muramatsu T, Nakagawa K, Shimono M, Suzuki T, Magloire

1177 H, Shibukawa Y. 2005. The odontoblast as a sensory receptor cell? The expression of

1178 TRPV1 (VR-1) channels. Archives of histology and cytology 68:251-257.

1179 Ørvig T. 1951. Histologic studies of Placoderms and fossil Elasmobranchs I: The

1180 endoskeleton, with remarks on the hard tissues of lower vertebrates in general. Arkiv för

1181 Zoologie 2:321-456.

1182 Ørvig T. 1966. Histologic studies of ostracoderms, placoderms and fossil

1183 elasmobranchs. 2. On the dermal skeleton of two late Palaeozoic Elasmobranchs. Arkiv

1184 för Zoologi 19:1-39.

1185 Ørvig T. 1968. The dermal skeleton: general considerations. In: Ørvig T, ed. Current

1186 problems of lower vertebrate phylogeny. Stockholm: Almquist and Wiksell, 374-397.

1187 Ørvig T. 1977. A survey of odontodes ('dermal teeth') from developmental, structural,

1188 functional, and phyletic points of view. In: Andrews M, R. S. \& Walker, A. D., ed.

1189 Problems in Vertebrate Evolution. London, New York: Academic Press, 53-75.

1190 Pradel A, Maisey JG, Tafforeau P, Mapes RH, Mallatt J. 2014. A Palaeozoic shark

1191 with osteichthyan-like branchial arches. Nature 509:608-611.

1192 Reif WE. 1978. Types of morphogenesis of the dermal skeleton in fossil sharks.

1193 Paläontologische Zeitschrift 52:110-128.

1194 Reif WE. 1980. Development of dentition and dermal skeleton in embryonic

1195 Scyliorhinus canicula. Journal of Morphology 166:275-288.

1196 Sansom IJ. 1996. Pseudooneotodus: a histological study of an Ordovician to Devonian

1197 vertebrate lineage. Zoological Journal of the Linnean Society 118:47-57. 
1198 Sansom IJ, Aldridge R, Smith M. 2000. A microvertebrate fauna from the Llandovery

1199 of South China. Transactions of the Royal Society of Edinburgh: Earth Sciences

$1200 \quad 90: 255-272$.

1201 Sansom IJ, Davies NS, Coates MI, Nicoll RS, Ritchie A. 2012. Chondrichthyan-like

1202 scales from the Middle Ordovician of Australia. Palaeontology 55:243-247.

1203 Sansom IJ, Smith MM, Smith MP. 1996. Scales of thelodont and shark-like fishes from

1204 the Ordovician of Colorado. Nature 379:628-630.

1205 Sansom IJ, Smith MM, Smith MP. 2001. The Ordovician radiation of vertebrates. In:

1206 Ahlberg E, ed. Major Events in Early Vertebrate Evolution, Systematics Association

1207 Special Volume. London and New York: Taylor \& Francis, 156-171.

1208 Sansom IJ, Wang NZ, Smith M. 2005. The histology and affinities of sinacanthid

1209 fishes: primitive gnathostomes from the Silurian of China. Zoological Journal of the

1210 Linnean Society 144:379-386.

1211 Sasagawa I. 1995. Evidence of two types of odontoblasts during dentinogenesis in

1212 Elasmobranchs. Connective tissue research 33:223-229.

1213 Schaumberg G. 1982. Hopleacanthus richelsdorfensis n. g. n. sp., ein Euselachier aus

1214 dem permischen Kupferschiefer von Hessen (W-Deutschland). Paläontologische

1215 Zeitschrift 56:235-257.

1216 Schmidt WJ, Keil A. 1971. Polarizing microscopy of dental tissues: Pergamon Press.

1217 Schultze H-P. 1968. Palaeoniscoidea-Schuppen aus dem Unterdevon Australiens und

1218 Kanadas und aus dem Mitteldevon Spitzbergens. Bulletin of the British Museum

1219 (Natural History) 16:343-368.

1220 Sennikov N, Rodina O, Izokh N, Obut O. 2015. New data on Silurian vertebrates of 
1221 southern Siberia. Palaeoworld 24:231-242.

1222 Servais T, Owen AW, Harper DA, Kröger B, Munnecke A. 2010. The great ordovician

1223 biodiversification event (GOBE): the palaeoecological dimension. Palaeogeography,

1224 Palaeoclimatology, Palaeoecology 294:99-119.

1225 Sire JY. 1994. Light and TEM study of nonregenerated and experimentally regenerated

1226 scales of Lepisosteus oculatus (Holostei) with particular attention to ganoine formation.

1227 The Anatomical Record 240:189-207.

1228 Sire JY. 2005. Development and fine structure of the bony scutes in Corydoras

1229 arcuatus (Siluriformes, Callichthyidae). Journal of Morphology 215:225-244.

1230 Sire JY, Donoghue PCJ, Vickaryous MK. 2009. Origin and evolution of the

1231 integumentary skeleton in non-tetrapod vertebrates. Journal of anatomy 214:409-440.

1232 Sire JY, Huysseune A. 1996. Structure and development of the odontodes in an

1233 armoured catfish, Corydoras aeneus (Siluriformes, Callichthyidae). Acta Zoologica

$1234 \quad 77: 51-72$.

1235 Sire JY, Huysseune A. 2003. Formation of dermal skeletal and dental tissues in fish: a

1236 comparative and evolutionary approach. Biological Reviews 78:219-249.

1237 Smith MM. 1979. Scanning electron microscopy of odontodes in the scales of a

1238 coelacanth embryo, Latimeria chalumnae Smith. Archives of oral biology 24:179-183.

1239 Smith MM, Hall BK. 1993. A developmental model for evolution of the vertebrate

1240 exoskeleton and teeth. Evolutionary biology: Springer, 387-448.

1241 Smith MM, Hobdell MH, Miller W. 1972. The structure of the scales of Latimeria

1242 chalumnae. Journal of Zoology 167:501-509.

1243 Smith MM, Sansom IJ, Smith MP. 1996. 'Teeth' before armour: The earliest vertebrate 
1244 mineralized issues. Modern Geology 20:303-319.

1245 StahI BJ. 1999. Chondrichthyes III: Holocephali. Munich: Verlag Dr. Friedrich Pfeil.

1246 Stensiö E. 1961. Permian vertebrates. In: Raasch G, ed. Geology of the Arctic.

1247 Toronto: University of Toronto, 231-247.

1248 Thorsteinsson R. 1973. Dermal elements of a new lower vertebrate from Middle

1249 Silurian (Upper Wenlockian) Rocks of the Canadian Arctic Archipelago.

1250 Palaeontographica Abteilung A 143:51-57.

1251 Turner S, Blieck A, Nowlan G. 2004. Vertebrates (agnathans and gnathostomes). In:

1252 Webby BD, Paris F, Droser ML, and Percival I, eds. The Great Ordovician

1253 Biodiversification Event: Columbia University Press, 327-335.

1254 Valiukevičius J. 1992. First articulated Poracanthodes from the Lower Devonian of

1255 Severnaya Zemlya. In: Mark-Kurik E, ed. Fossil Fishes as Living Animals. Tallinn:

1256 Academy of Sciences of Estonia, 193-214.

1257 Valiukevičius J. 2003. Devonian acanthodians from Severnaya Zemlya Archipelago

1258 (Russia). Geodiversitas 25:131-204.

1259 Valiukevičius J, Burrow CJ. 2005. Diversity of tissues in acanthodians with

1260 Nostolepis-type histological structure. Acta Palaeontologica Polonica 50:635-649.

1261 Wang N-Z, Zhang S-B, Wang J-Q, Zhu M. 1998. Early Silurian chondrichthyan

1262 microfossils from Bachu County, Xinjiang, China. Vertebrata PalAsiatica 36:257-267.

1263 Wang R. 1993. Taxonomie, Palökologie und Biostratigraphie der Mikroichthyolithen aus

1264 dem Unterdevon Keltiberiens, Spanien. Frankfurt a. M.: Senckenbergische

1265 Naturforschende Gesellschaft.

1266 Webby BD, Paris F, Droser ML. 2004. The great Ordovician biodiversification event. 
1267 New York: Columbia University Press.

1268 Williams ME. 1998. A new specimen of Tamiobatis vetustus (Chondrichthyes,

1269 Ctenacanthoidea) from the late Devonian Cleveland Shale of Ohio. Journal of

1270 Vertebrate Paleontology 18:251-260.

1271 Yoshiba K, Yoshiba N, Ejiri S, Iwaku M, Ozawa H. 2002. Odontoblast processes in

1272 human dentin revealed by fluorescence labeling and transmission electron microscopy.

1273 Histochemistry and cell biology 118:205-212.

1274 Young G. 1982. Devonian sharks from south-eastern Australia and Antarctica.

1275 Palaeontology 25:817-843.

1276 Zangerl R. 1966. A new shark of the family Edestidae, Ornithoprion hertwigi, from the

1277 Pennslyvanian Mecca and Logan quarry shales of Indiana. Fieldiana: Geology 16:1-43.

1278 Zangerl R. 1968. The morphology and the developmental history of the scales of the

1279 Paleozoic sharks Holmesella? sp. and Orodus. In: Ørvig T, ed. Current Problems of

1280 Lower Vertebrate Phylogeny. Stockholm: Almqvist \& Wiksell, 399-412.

1281 Zangerl R. 1981. Chondrichthyes I: Paleozoic Elasmobranchii. Stuttgart and New York:

1282 Gustav Fischer.

1283 Zeng XY. 1988. Some fin-spines of Acanthodii from Early Silurian of Hunan, China.

1284 Vertebrata Palasiatica 26:287-295.

1285 Zhu M. 1998. Early Silurian sinacanths (Chondrichthyes) from China. Palaeontology

$1286 \quad 41: 157-172$.

1287 Zhu M, Yu X, Ahlberg PE, Choo B, Lu J, Qiao T, Qu Q, Zhao W, Jia L, Blom H.

1288 2013. A Silurian placoderm with osteichthyan-like marginal jaw bones. Nature 502:1881289193. 
1290 Žigaitè Ž. 2004. A new thelodont from Lower Silurian of Tuva and north-west Mongolia.

1291 Acta Universitatis Latviensis 679:158-165.

1292 Žigaitè Ž. 2013. Endemic thelodonts (Vertebrata: Thelodonti) from the Lower Silurian of

1293 central Asia and southern Siberia. Earth and Environmental Science Transactions of the

1294 Royal Society of Edinburgh 104:123-143.

1295 Žigaitè Ž, Karatajūtè-Talimaa V. 2008. New genus of chondrichthyans from the

1296 Silurian-Devonian boundary deposits of Tuva (Russia). Acta Geologica Polonica

$1297 \quad 58: 127-131$.

1298 Žigaitè Ž, Karatajūtè-Talimaa V, Blieck A. 2011. Vertebrate microremains from the

1299 Lower Silurian of Siberia and Central Asia: palaeobiodiversity and palaeobiogeography.

1300 Journal of Micropalaeontology 30:97-106.

1301 Zylberberg L, Géraudie J, Meunier F, and Sire J. 1992. Biomineralization in the

1302 integumental skeleton of the living lower vertebrates. In: Hall BK, ed. Bone: Vol. 4:

1303 bone metabolism and mineralization: CRC Press Inc., 171-224.

1304

1305

1306

1307

1308

1309 


\section{Figure captions}

1314 Figure 1 Principle morphological features of scales. Line drawing of a Mongolepis

1315 scale (BU5296) from the Chargat Formation of north-western Mongolia in lateral view.

1316 Figure 2 Character distribution within Mongolepidida. Cladogram based on a yet

1317 to be published scale-based phylogeny of early chondrichthyans by Andreev, Coates

1318 \& Sansom (unpublished). Portion of a majority-rule consensus tree generated in TNT

1319 version 1.1 (Goloboff, Farris \& Nixon, 2008) using a data matrix of 68 equally weighted

1320 scale-based characters (53 original and 15 revised/adopted) and 49 Palaeozoic

1321 jawed-gnathostome taxa.

1322 Figure 3 Scale morphology of Mongolepididae. (A-C) Mongolepis rozmanae scale

1323 BU5296 (Chargat Formation, north-western Mongolia) in (A) anterior (B) lateral, (C) and

1324 basal aspect and a M. rozmanae scale in (D) crown view (BU5351, Chargat Formation,

1325 north-western Mongolia); (E, G) Teslepis jucunda BU5322 (Chargat Formation, north-

1326 western Mongolia) in (E) crown and (G) basal view and a T. jucunda scale (BU5352,

1327 Chargat Formation, north-western Mongolia) in an (F) antero-lateral view; (H-J)

1328 Sodolepis lucens scales (Chargat Formation, north-western Mongolia) in (H) lateral

1329 (BU5305), crown (BU5304) and (J) basal (BU5355) views; (K-M) Rongolepis cosmetica 
1330 scale BU5303 (Xiushan Formation, south China) in (K) crown, (L) lateral and (M) basal

1331 views;. Volume renderings, $(A-C),(H)$ and (K-M); SEM micrographs, (D-G) and (I, J).

1332 Crown and base foramina indicated by arrows and arrowheads respectively. Anterior to

1333 the left in $(B),(H),(L)$ and bottom in $(A-G),(H-K),(M)$. Scale bar equals $500 \mu m$ in (D,

$1334 \mathrm{I}, \mathrm{J}), 400 \mu \mathrm{m}$ in (A-C), $300 \mu \mathrm{m}$ in $(\mathrm{H}, \mathrm{K})$ and $200 \mu \mathrm{m}$ in (E-G, L, M).

1335 Figure 4 Scale morphology of Shiqianolepidae. (A-C) Shiqianolepis hollandi scales

1336 (Xiushan Formation, south China) in (A) lateral (NIGP 130307), (B) crown (NIGP

1337 130309) and (C) postero-basal (NIGP 130307) views; (D-F) Xinjiangichthys

1338 pluridentatus scale IVPP V X2 (Yimugantawu Formation, north-western China) in (D)

1339 anterior, $(E)$ posterior and $(F)$ antero-lateral views. All images volume renderings except

1340 (B). Crown foramina indicated by arrows. Anterior to the left in $(A)$, to the right in $(F)$ and

1341 bottom in (B). Scale bar equals $300 \mu \mathrm{m}$ in (A, B) and $200 \mu \mathrm{m}$ in (C-F).

1342 Figure 5 SEM micrographs of Solinalepis levis gen. et sp. nov. scales from the

1343 Upper Ordovician Harding Sandstone of Colorado, USA. (A-C) tessera-like head

1344 scales in (A, B) crown (BU5307, BU5308) and (C) lateral (BU5309) views; (D) bulbous

1345 head scale (BU5312) in lateral view; (E-I) polygonal trunk scales, (E) holotype

1346 (BU5310) in anterior view, $(F)$ BU5345 in crown, $(G)$ corono-lateral and $(H)$ partial

1347 posterior views, (I) BU5313 in basal view; J-L, lanceolate trunk scales in (J) anterior

1348 (BU5314), (K) lateral (BU5315) and (L) posterior (BU5311) views. Base foramina

1349 indicated by arrowheads. Anterior to the left in $(G)$ and $(K)$. Scale bar equals $300 \mu \mathrm{m}$

1350 in (A, B), $200 \mu \mathrm{m}$ in (C), $100 \mu \mathrm{m}$ in (D-G, $\mathrm{I}-\mathrm{L})$, and $50 \mu \mathrm{m}$ in $(\mathrm{H})$. 
1351 Figure 6 Scale histology of Mongolian and Chinese mongolepids. (A) medial

1352 longitudinal section of a Mongolepis rozmanae scale (BU5297; Chargat Formation,

1353 north-western Mongolia); (B) detail of (A) depicting primary and secondary odontodes at

1354 the anterior crown margin; (C) primary odontode lamellin microstructure in a

1355 longitudinally sectioned Mongolepis rozmanae scale (BU5298; Chargat Formation,

1356 north-western Mongolia), etched for 10 min in $0.5 \%$ orthophosphoric acid; (D) basal

1357 bone microstructure of a longitudinally sectioned Mongolepis rozmanae scale (BU5354;

1358 Chargat Formation, north-western Mongolia) etched for $10 \mathrm{~min}$ in $0.5 \%$ orthophosphoric

1359 acid; (E) detail of BU5354 depicting the bone tissue of the anterior basal platform; (F)

1360 medial longitudinal section of a Teslepis jucunda scale (BU5324; Chargat Formation,

1361 north-western Mongolia); (G) lamellin architecture of two odontodes in a longitudinally

1362 sectioned Sodolepis lucens scale (BU5306; Chargat Formation, north-western

1363 Mongolia) etched for 10 min in $0.5 \%$ orthophosphoric acid; $(\mathrm{H})$ basal bone

1364 microstructure in BU5306 at the anterior projection of the base; (I), sagittal longitudinal

1365 section of a Sodolepis lucens scale (BU5344; Chargat Formation, north-western

1366 Mongolia); (J) anterior third of BU5306 showing the contact between the globular crown

1367 dentine and the underlying basal bone; $(K)$ sagittal longitudinal section of a Rongolepis

1368 cosmetica scale (NIGP 130328; Xiushan Formation, south China); (L) detail of NIGP

1369130328 showing the mid third of the scale crown; (M) Xinjiangichthys pluridentatus

1370 scale (IVPP V X1; Yimugantawu Formation, north-western China) in longitudinal

1371 section; (N) sagittal longitudinal section of a Shiqianolepis hollandi trunk scale (NIGP

1372 130312; Xiushan Formation, south China). Nomarski differential interference contrast

1373 optics micrographs, (A), (B), (D), (F), (G), (I) and (K-N); SEM micrographs, (C), (E), (H) 
1374 and $(J)$. Anterior towards the left in $(A-J, L)$ and towards the right in $(K),(M)$ and $(N)$.

1375 Abbreviations: gb, globular dentine; lb, lamellar bone; red dotted lines, contact surfaces

1376 between primary and secondary odontodes; white dotted lines, border between globular

1377 dentine and basal bone; white dashed line, contact surfaces between primary

1378 odontodes in Rongolepis. Asterisks mark bone layers with fibre orientation parallel to

1379 the section axis. Scale bar equals $400 \mu \mathrm{m}$ in (A), $100 \mu \mathrm{m}$ in (B, $G, H, M), 20 \mu \mathrm{m}$ in (C),

$1380200 \mu \mathrm{m}$ in (D, F, K, N), $50 \mu \mathrm{m}$ in (E, J, L), and $300 \mu \mathrm{m}$ in (I).

1381 Figure 7 Histology of Solinalepis levis gen. et sp. nov. scales. (A) thin-sectioned

1382 head scale (BU5317) from the Harding Sandstone, Colorado, USA; (B) transverse

1383 section of a Solinalepis levis gen. et sp. nov. trunk scale (BU5316) from the Harding

1384 Sandstone, Colorado, USA. Scale bar equals $200 \mu \mathrm{m}$ in (A) and $100 \mu \mathrm{m}$ in (B).

1385 Figure 8 Canal system of mongolepid scales. Volume renderings. (A-C) canals (red)

1386 inside a translucent Mongolepis rozmanae scale (BU5296) in (A) lateral view, in (B)

1387 posterior view sliced along the plane 1 and in $(C, C 1)$ crown view sliced along plane 2;

1388 (D, D1) canals in a transversely sliced Teslepis jucunda scale (BU5325) shown in

1389 posterior view; (E) pulp cavities (red) in a transversely sliced Sodolepis lucens scale

1390 (BU5305) shown in postero-lateral view; (F) longitudinally sliced Shiqianolepis hollandi

1391 scale (NIGP 130307) in baso-lateral view; (G, H) longitudinally sliced Xinjiangichthys

1392 pluridentatus scale IVPP V X2 in (G) posterior and $(\mathrm{H})$ lateral views; $(\mathrm{I}, \mathrm{J})$ canals system

1393 (red) inside a transversely sliced Solinalepis levis gen. et sp. nov. scale (BU5318)

1394 shown in posterior view, $(\mathrm{J})$ detail of $(\mathrm{I})$. Horizontal canals depicted in purple in c1 and

1395 d1. Yellow arrowheads point at canal openings on the sub-crown surface. Red dotted

1396 line, contact surfaces between primary and secondary odontodes; grey dotted line, 
1397 crown/base border. Scale bar equals $400 \mu \mathrm{m}$ in (A-C), $100 \mu \mathrm{m}$ in (D, H, I), $200 \mu \mathrm{m}$ in

1398 (E), $300 \mu \mathrm{m}(\mathrm{F}, \mathrm{G})$ and $50 \mu \mathrm{m}$ in $(\mathrm{J})$.

1399 Figure 9 Odontocomplex organization of mongolepid scale crowns. (A) Teslepis

1400 jucunda (BU5323) scale, medial portion of the crown; (B) Shiqianolepis hollandi (NIGP

1401 130309) scale, medial portion of the crown; (C) Solinalepis levis gen. et sp. nov. trunk

1402 scale (BU5314), lateral portion of the crown. Primary odontocomplex structure in

1403 Mongolepidida demonstrated by line drawings of longitudinally sectioned (D)

1404 Mongolepis rozmanae (BU5297) and (E) Shiqianolepis hollandi (NIGP 130312) scales.

1405 In (A-C) some of the odontocomplexes are highlighted in red and green. Dark green

1406 and dark red, odd numbered odontodes; light green and light red, even numbered

1407 odontodes. In (D, E)—light grey, primary odontodes; light yellow, secondary odontodes.

1408 Anterior towards the bottom in $(A-C)$ and towards the left in (D, E). Scale bar equals

$1409100 \mu \mathrm{m}$ in (A), $200 \mu \mathrm{m}$ in (B) and $50 \mu \mathrm{m}$ in (C). 


\section{1}

Principle morphological features of scales

Figure 1 Principle morphological features of scales. Line drawing of a Mongolepis scale (BU5296) from the Chargat Formation of north-western Mongolia in lateral view.

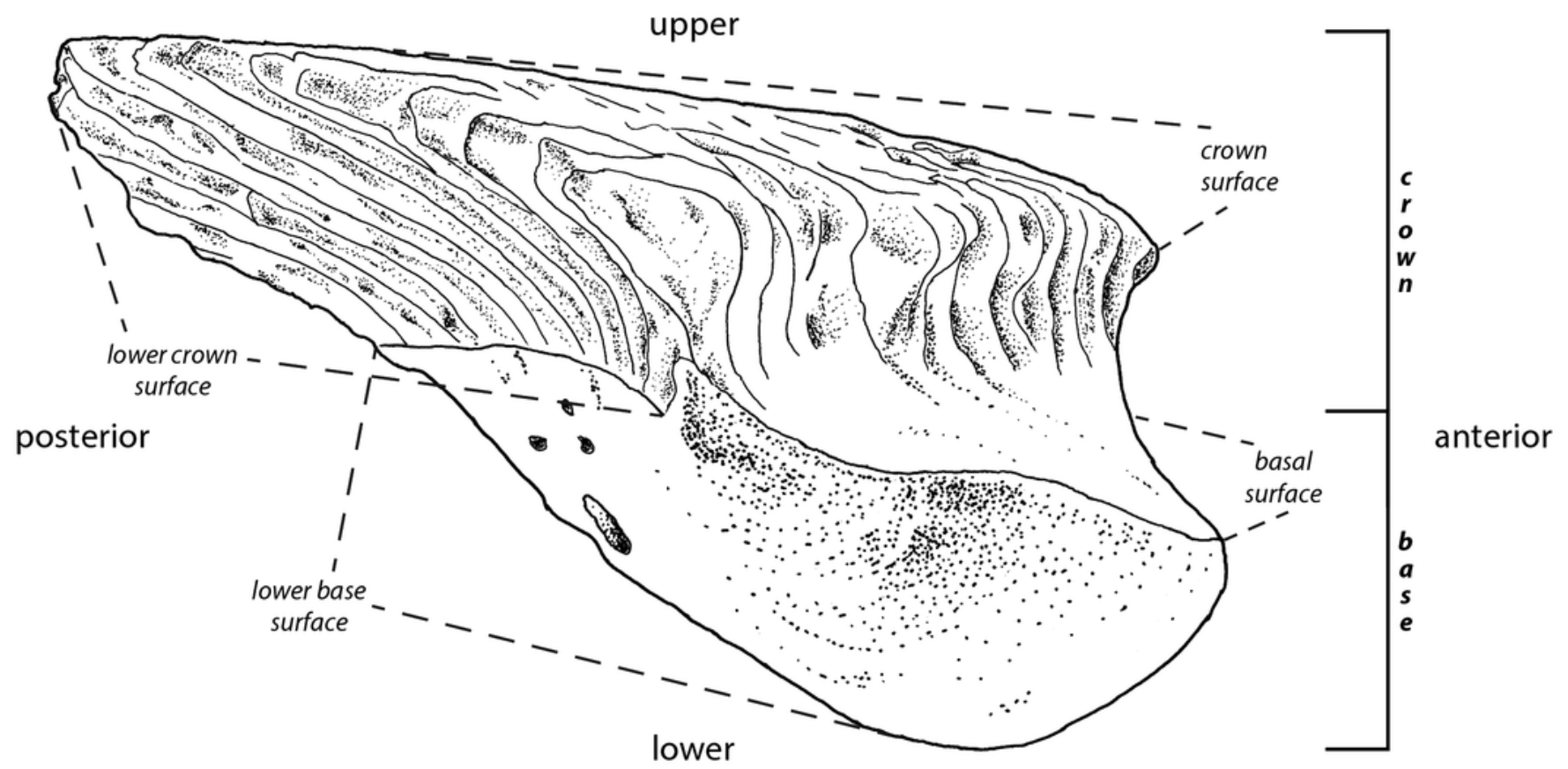




\section{2}

Character distribution within Mongolepidida

Figure 2 Character distribution within Mongolepidida. Cladogram based on a yet to be published scale-based phylogeny of early chondrichthyans by Andreev, Coates $\&$ Sansom (unpublished). Portion of a majority-rule consensus tree generated in TNT version 1.1 (Goloboff, Farris \& Nixon, 2008) using a data matrix of 68 equally weighted scale-based characters (53 original and 15 revised/adopted) and 49 Palaeozoic jawed-gnathostome taxa.

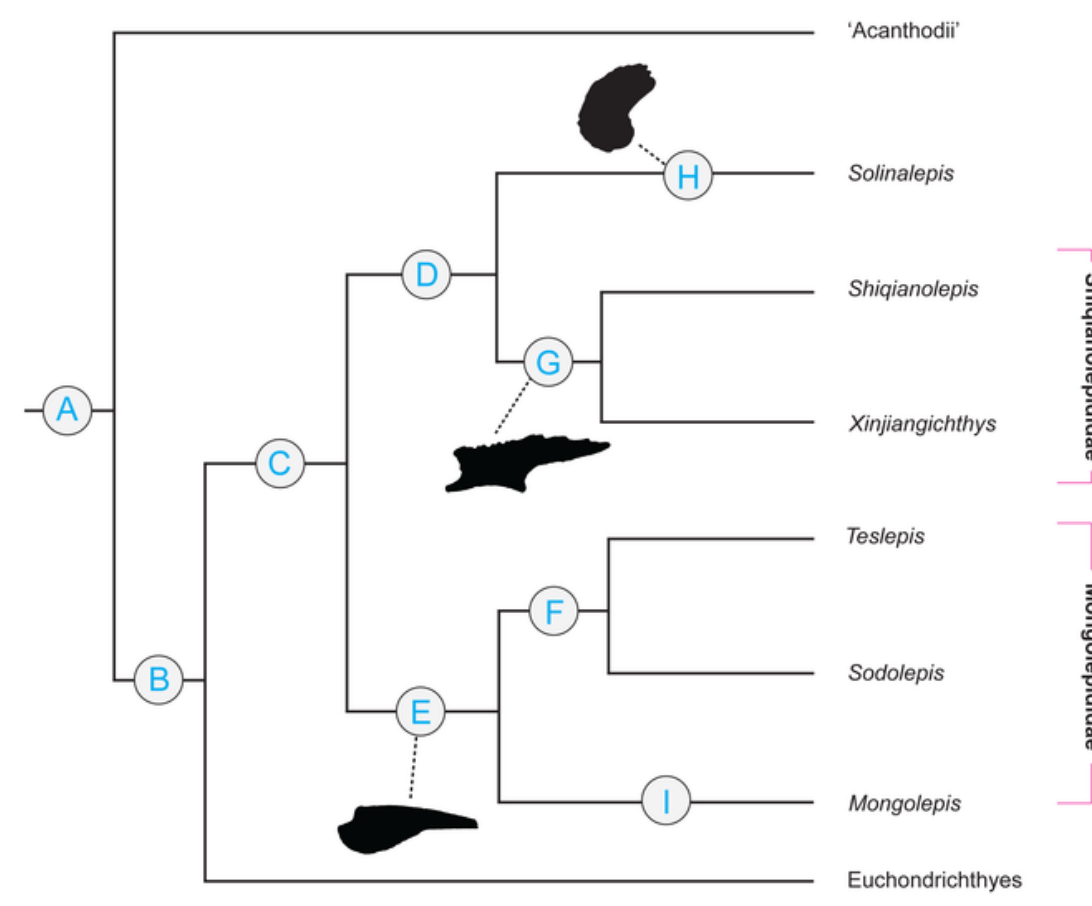

- neck canals

all primary scale odontodes exposed on the crown surface - bases of trunk scales widest at their middle thir absence of trunk scales with

peg-and-socket articulation
- bilaterally symmetrical trunk scales

scales - absence of scale hard-tissue resorption

- absence of basal bone osteons

- crown primordium developed at the anterior third of the scale - odontode size remains constant in the direction of the lateral crown margins

- atubular dentine

C - spheritic dentine minerlization - polyodontocomplex crown

- trunk scale base not extended beyond the anterior crown margin - acellular basal bone - convex base - scale-base canal system

- crescent-shaped anterior crown platform - lateral sides of trunk-scale bases extended beyond the crown margins

crown extended by half or more of its length beyond the base margin - constricted lower portion of trunk

G scale crowns - concave lower-base surface - absence of scale-base canal system - cellular basal bone

- absence of neck canals - scale-base canal system

- canal openings at the upper base surface of trunk scales

- planar crown/base contact surface

| - pore-canal system 


\section{3}

Scale morphology of Mongolepididae

Figure 3 Scale morphology of Mongolepididae. (A-C) Mongolepis rozmanae scale BU5296 (Chargat Formation, north-western Mongolia) in (A) anterior (B) lateral, (C) and basal aspect and a M. rozmanae scale in (D) crown view (BU5351, Chargat Formation, northwestern Mongolia); (E, G) Teslepis jucunda BU5322 (Chargat Formation, north-western Mongolia) in (E) crown and (G) basal view and a T. jucunda scale (BU5352, Chargat Formation, north-western Mongolia) in an (F) antero-lateral view; (H-J) Sodolepis lucens scales (Chargat Formation, north-western Mongolia) in (H) lateral (BU5305), crown (BU5304) and (J) basal (BU5355) views; (K-M) Rongolepis cosmetica scale BU5303 (Xiushan Formation, south China) in (K) crown, (L) lateral and (M) basal views; . Volume renderings, $(A-C),(H)$ and (K-M); SEM micrographs, (D-G) and (I, J). Crown and base foramina indicated by arrows and arrowheads respectively. Anterior to the left in $(B),(H),(L)$ and bottom in $(A-G),(H-K),(M)$. Scale bar equals $500 \mu \mathrm{m}$ in (D, I, J), $400 \mu \mathrm{m}$ in (A-C), $300 \mu \mathrm{m}$ in $(\mathrm{H}, \mathrm{K})$ and $200 \mu \mathrm{m}$ in (E-G, L, M). 


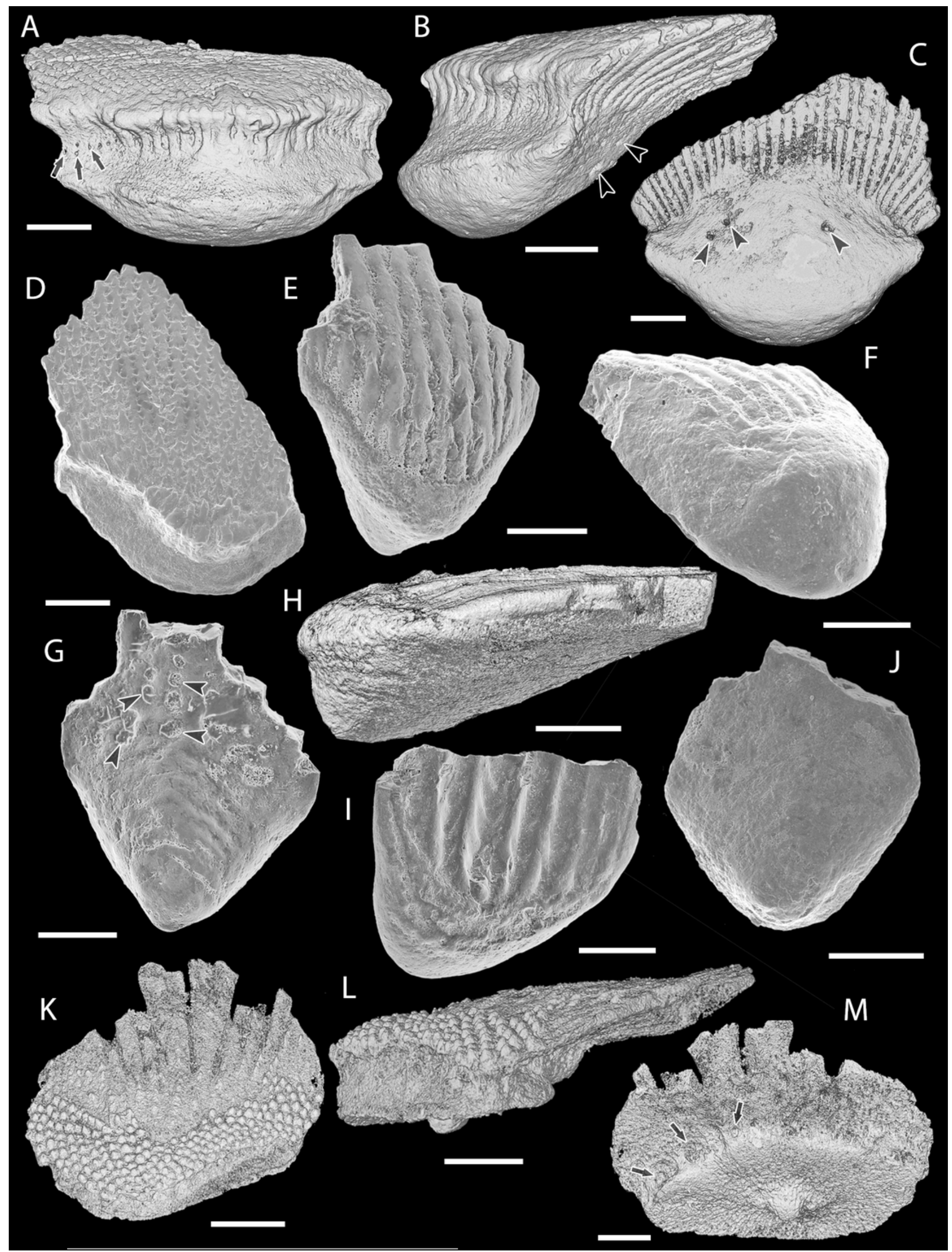


4

Scale morphology of Shiqianolepidae

Figure 4 Scale morphology of Shiqianolepidae. (A-C) Shiqianolepis hollandi scales

(Xiushan Formation, south China) in (A) lateral (NIGP 130307), (B) crown (NIGP 130309) and

(C) postero-basal (NIGP 130307) views; (D-F) Xinjiangichthys pluridentatus scale IVPP V X2

(Yimugantawu Formation, north-western China) in (D) anterior, (E) posterior and (F) antero-

lateral views. All images volume renderings except (B). Crown foramina indicated by arrows.

Anterior to the left in (A), to the right in (F) and bottom in (B). Scale bar equals $300 \mu \mathrm{m}$ in (A,

B) and $200 \mu \mathrm{m}$ in (C-F).

*Note: Auto Gamma Correction was used for the image. This only affects the reviewing manuscript. See original source image if needed for review.

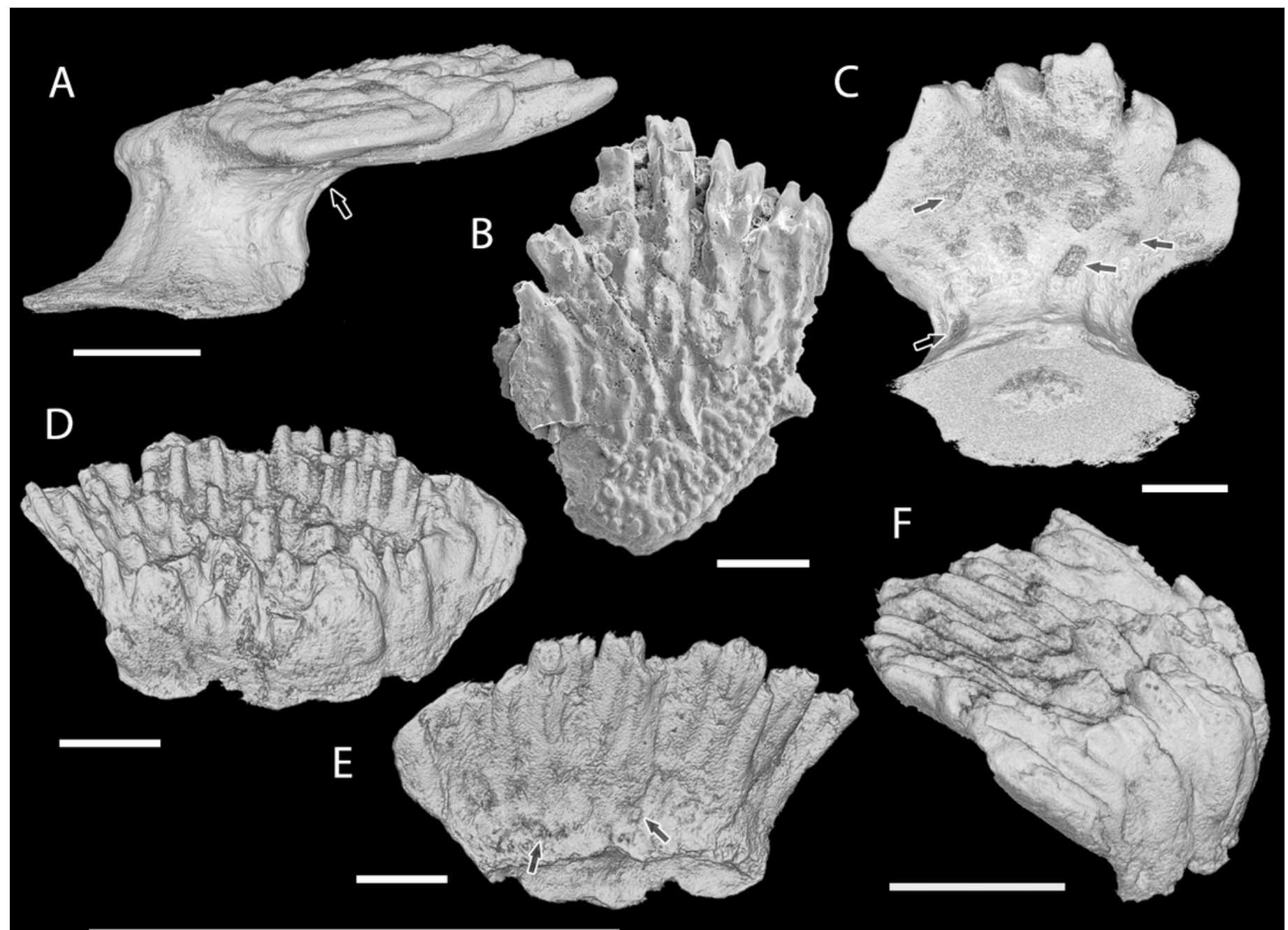


5

SEM micrographs of Solinalepis levis gen. et sp. nov. scales

Figure 5 SEM micrographs of Solinalepis levis gen. et sp. nov. scales from the Upper Ordovician Harding Sandstone of Colorado, USA. (A-C) tessera-like head scales in (A, B) crown (BU5307, BU5308) and (C) lateral (BU5309) views; (D) bulbous head scale (BU5312) in lateral view; (E-I) polygonal trunk scales, (E) holotype (BU5310) in anterior view, (F) BU5345 in crown, (G) corono-lateral and (H) partial posterior views, (I) BU5313 in basal view; J-L, lanceolate trunk scales in (J) anterior (BU5314), (K) lateral (BU5315) and (L) posterior (BU5311) views. Base foramina indicated by arrowheads. Anterior to the left in (G) and (K). Scale bar equals $300 \mu \mathrm{m}$ in (A, B), $200 \mu \mathrm{m}$ in (C), $100 \mu \mathrm{m}$ in (D-G, I-L), and $50 \mu \mathrm{m}$ in (H).

*Note: Auto Gamma Correction was used for the image. This only affects the reviewing manuscript. See original source image if needed for review. 


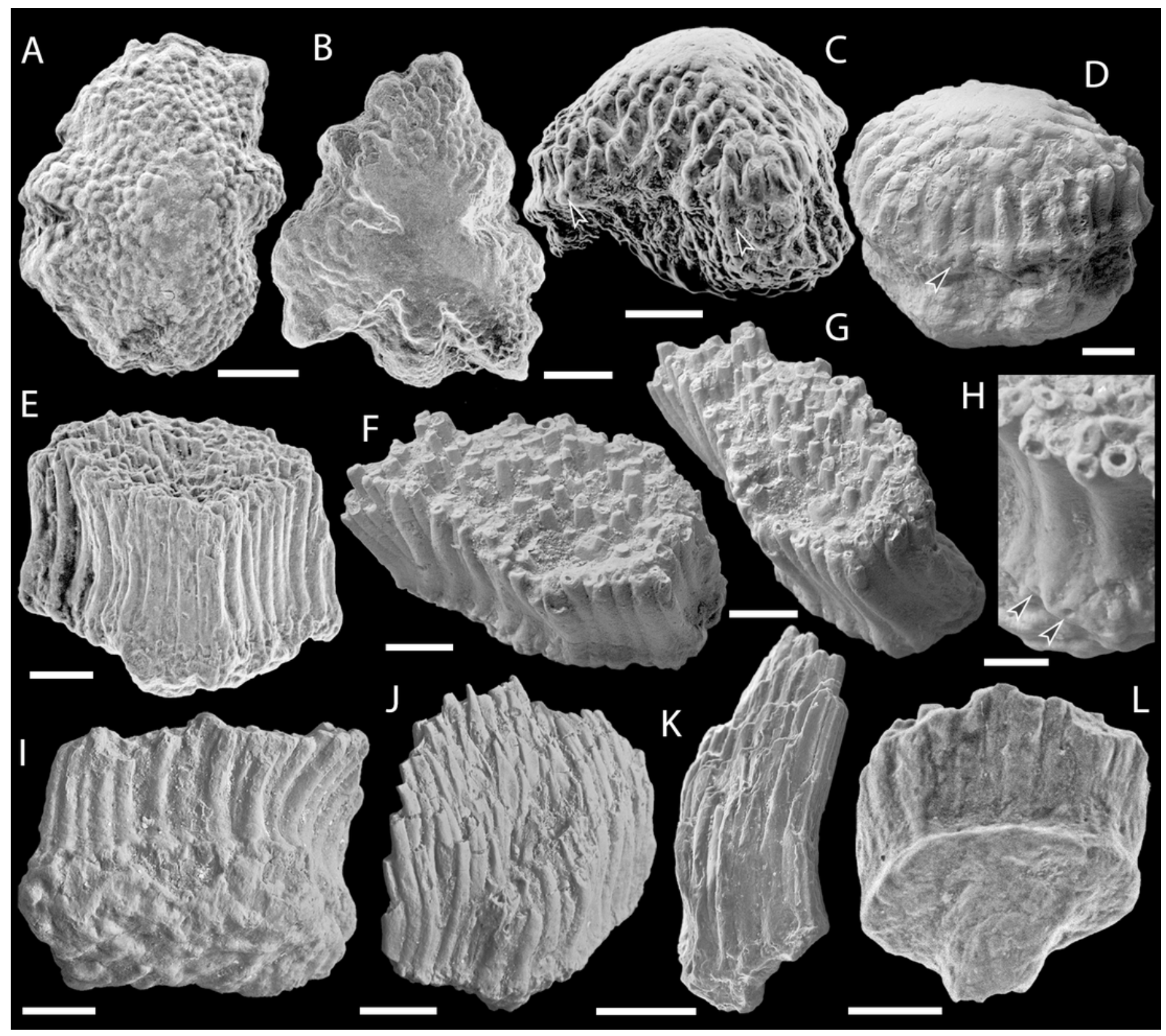


6

Scale histology of Mongolian and Chinese mongolepids

Figure 6 Scale histology of Mongolian and Chinese mongolepids. (A) medial longitudinal section of a Mongolepis rozmanae scale (BU5297; Chargat Formation, northwestern Mongolia); (B) detail of (A) depicting primary and secondary odontodes at the anterior crown margin; (C) primary odontode lamellin microstructure in a longitudinally sectioned Mongolepis rozmanae scale (BU5298; Chargat Formation, north-western Mongolia), etched for $10 \mathrm{~min}$ in $0.5 \%$ orthophosphoric acid; (D) basal bone microstructure of a longitudinally sectioned Mongolepis rozmanae scale (BU5354; Chargat Formation, northwestern Mongolia) etched for 10 min in $0.5 \%$ orthophosphoric acid; (E) detail of BU5354 depicting the bone tissue of the anterior basal platform; (F) medial longitudinal section of a Teslepis jucunda scale (BU5324; Chargat Formation, north-western Mongolia); (G) lamellin architecture of two odontodes in a longitudinally sectioned Sodolepis lucens scale (BU5306; Chargat Formation, north-western Mongolia) etched for $10 \mathrm{~min}$ in $0.5 \%$ orthophosphoric acid; (H) basal bone microstructure in BU5306 at the anterior projection of the base; (I), sagittal longitudinal section of a Sodolepis lucens scale (BU5344; Chargat Formation, north-western Mongolia); (J) anterior third of BU5306 showing the contact between the globular crown dentine and the underlying basal bone; $(\mathrm{K})$ sagittal longitudinal section of a Rongolepis cosmetica scale (NIGP 130328; Xiushan Formation, south China); (L) detail of NIGP 130328 showing the mid third of the scale crown; (M) Xinjiangichthys pluridentatus scale (IVPP V X1; Yimugantawu Formation, north-western China) in longitudinal section; (N) sagittal longitudinal section of a Shiqianolepis hollandi trunk scale (NIGP 130312; Xiushan Formation, south China). Nomarski differential interference contrast optics micrographs, (A), (B), (D), (F), (G), (I) and (K-N); SEM micrographs, (C), (E), (H) and (J). Anterior towards the left in (A-J, L) and towards the right in (K), (M) and (N). Abbreviations: gb, globular dentine; lb, lamellar bone; red dotted lines, contact surfaces between primary and secondary odontodes; white PeerJ reviewing PDF | (2014:12:3352:2:0:NEW 4 Mar 2016) 
dotted lines, border between globular dentine and basal bone; white dashed line, contact surfaces between primary odontodes in Rongolepis. Asterisks mark bone layers with fibre orientation parallel to the section axis. Scale bar equals $400 \mu \mathrm{m}$ in $(A), 100 \mu \mathrm{m}$ in $(B, G, H$, M), $20 \mu \mathrm{m}$ in (C), $200 \mu \mathrm{m}$ in (D, F, K, N), $50 \mu \mathrm{m}$ in (E, J, L), and $300 \mu \mathrm{m}$ in (I). 


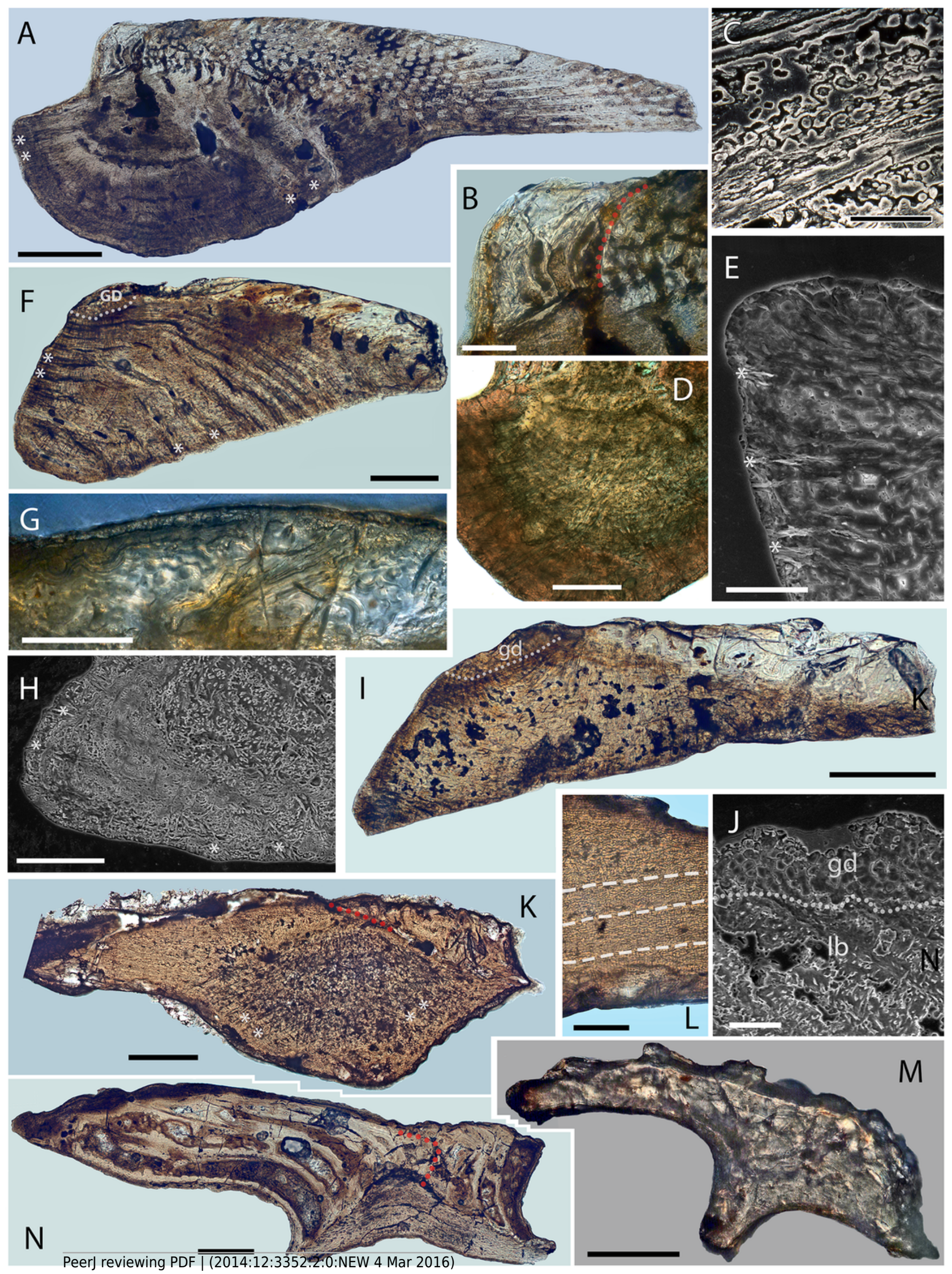




\section{7}

Histology of Solinalepis levis gen. et sp. nov. scales

Figure 7 Histology of Solinalepis levis gen. et sp. nov. scales. (A) thin-sectioned head scale (BU5317) from the Harding Sandstone, Colorado, USA; (B) transverse section of a Solinalepis levis gen. et sp. nov. trunk scale (BU5316) from the Harding Sandstone, Colorado, USA. Scale bar equals $200 \mu \mathrm{m}$ in (A) and $100 \mu \mathrm{m}$ in (B). 

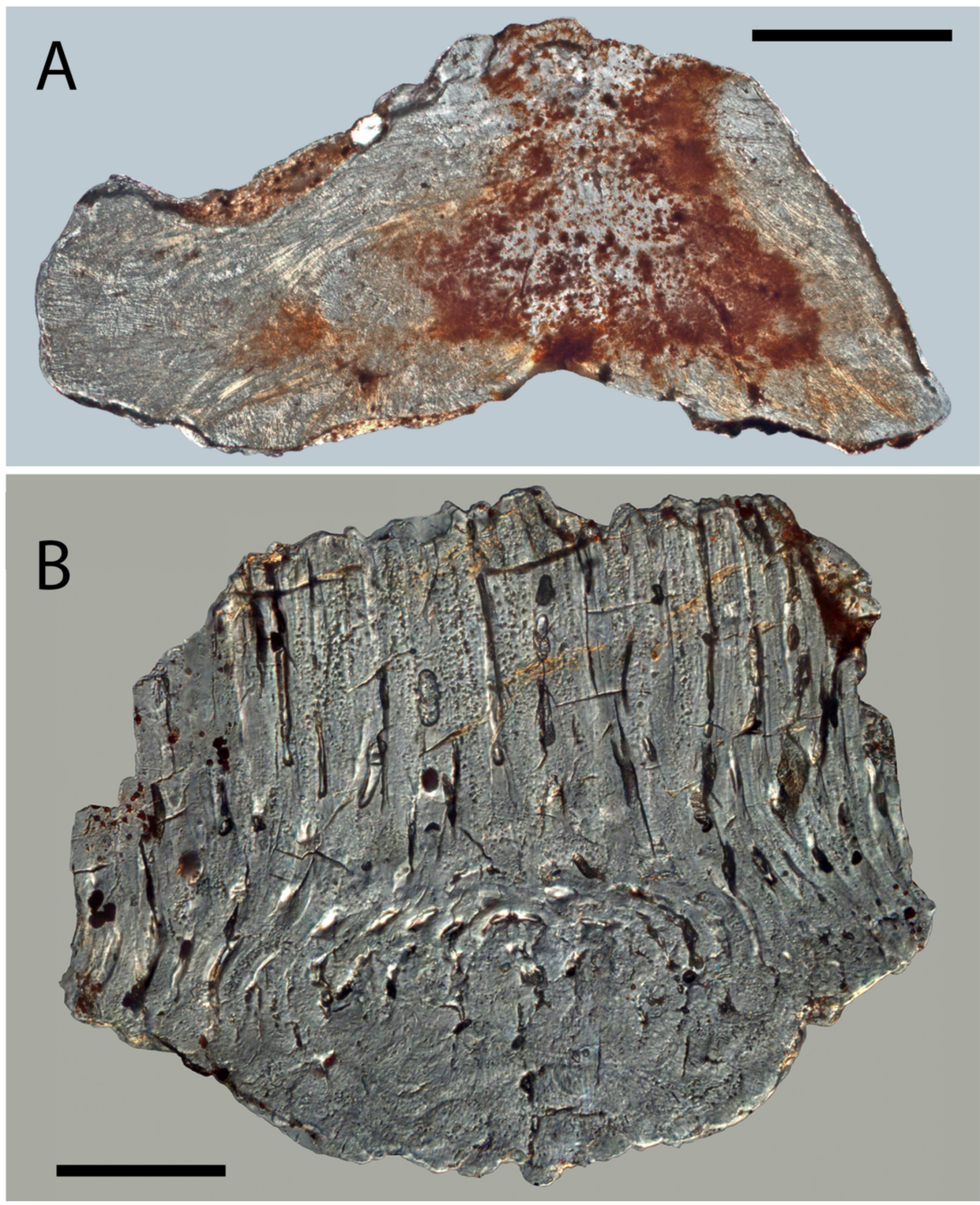
8

Canal system of mongolepid scales

Figure 8 Canal system of mongolepid scales. Volume renderings. (A-C) canals (red) inside a translucent Mongolepis rozmanae scale (BU5296) in (A) lateral view, in (B) posterior view sliced along the plane 1 and in (C, C1) crown view sliced along plane 2; (D, D1) canals in a transversely sliced Teslepis jucunda scale (BU5325) shown in posterior view; (E) pulp cavities (red) in a transversely sliced Sodolepis lucens scale (BU5305) shown in posterolateral view; (F) longitudinally sliced Shiqianolepis hollandi scale (NIGP 130307) in basolateral view; $(G, H)$ longitudinally sliced Xinjiangichthys pluridentatus scale IVPP V X2 in (G) posterior and (H) lateral views; (I, J) canals system (red) inside a transversely sliced Solinalepis levis gen. et sp. nov. scale (BU5318) shown in posterior view, (J) detail of (I). Horizontal canals depicted in purple in $\mathrm{cl}$ and $\mathrm{d} 1$. Yellow arrowheads point at canal openings on the sub-crown surface. Red dotted line, contact surfaces between primary and secondary odontodes; grey dotted line, crown/base border. Scale bar equals $400 \mu \mathrm{m}$ in (A-C), $100 \mu \mathrm{m}$ in $(\mathrm{D}, \mathrm{H}, \mathrm{I}), 200 \mu \mathrm{m}$ in $(\mathrm{E}), 300 \mu \mathrm{m}(\mathrm{F}, \mathrm{G})$ and $50 \mu \mathrm{m}$ in (J). 


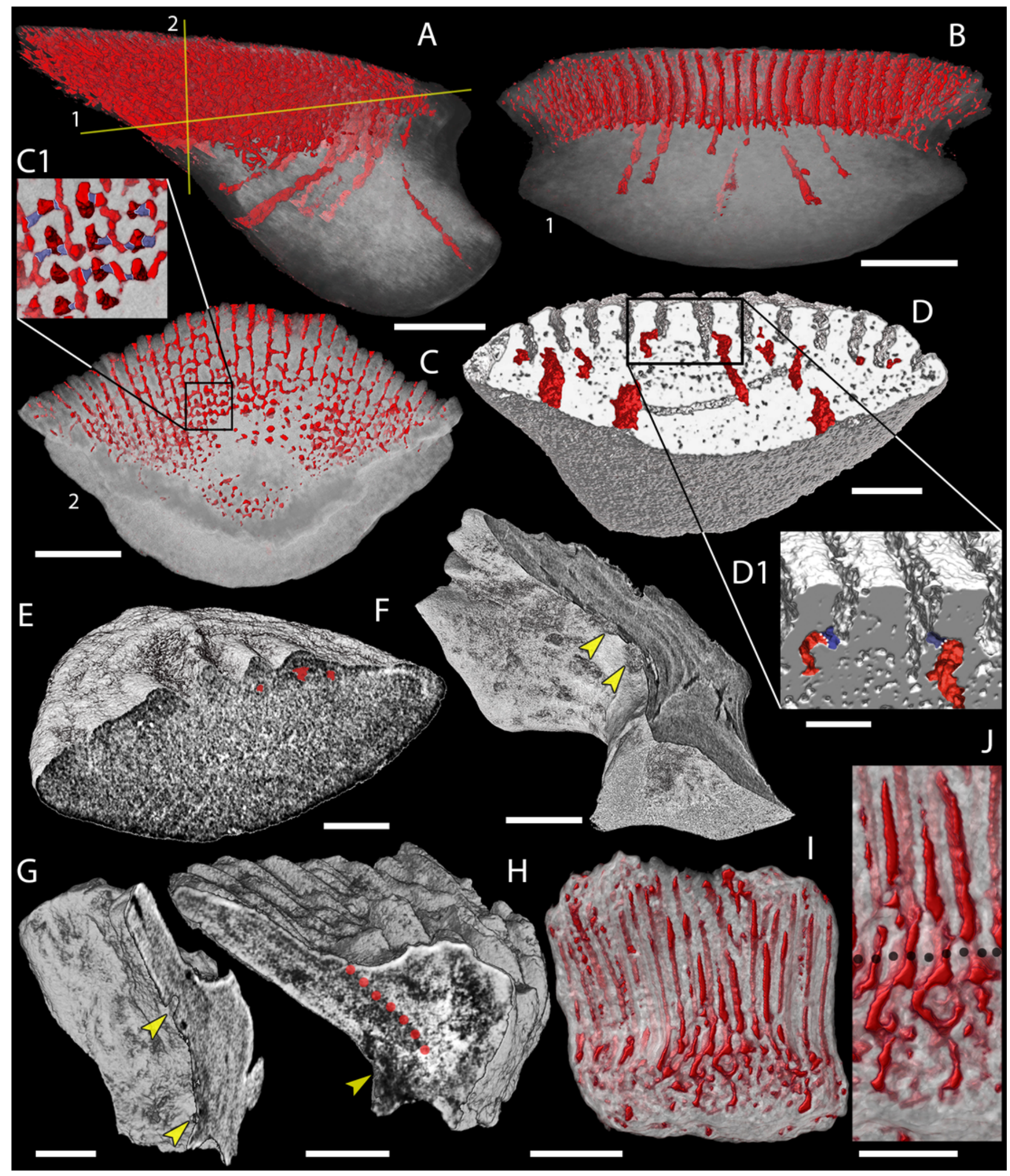


9

Odontocomplex organization of mongolepid scale crowns

Figure 9 Odontocomplex organization of mongolepid scale crowns. (A) Teslepis

jucunda (BU5323) scale, medial portion of the crown; (B) Shiqianolepis hollandi (NIGP 130309) scale, medial portion of the crown; (C) Solinalepis levis gen. et sp. nov. trunk scale (BU5314), lateral portion of the crown. Primary odontocomplex structure in Mongolepidida demonstrated by line drawings of longitudinally sectioned (D) Mongolepis rozmanae (BU5297) and (E) Shiqianolepis hollandi (NIGP 130312) scales. In (A-C) some of the odontocomplexes are highlighted in red and green. Dark green and dark red, odd numbered odontodes; light green and light red, even numbered odontodes. In (D, E)-light grey, primary odontodes; light yellow, secondary odontodes. Anterior towards the bottom in (A-C) and towards the left in (D, E). Scale bar equals $100 \mu \mathrm{m}$ in (A), $200 \mu \mathrm{m}$ in (B) and $50 \mu \mathrm{m}$ in (C). 


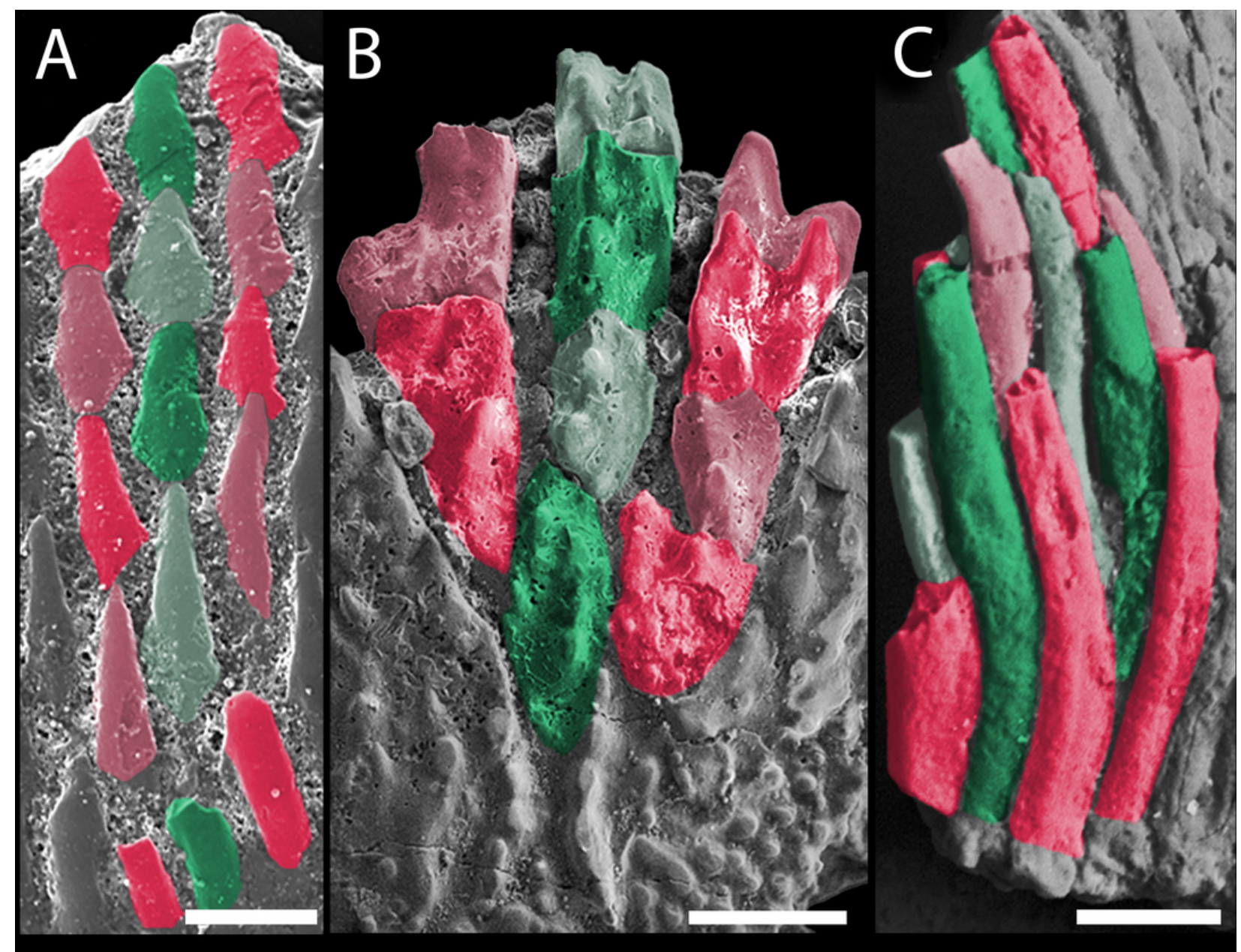

D

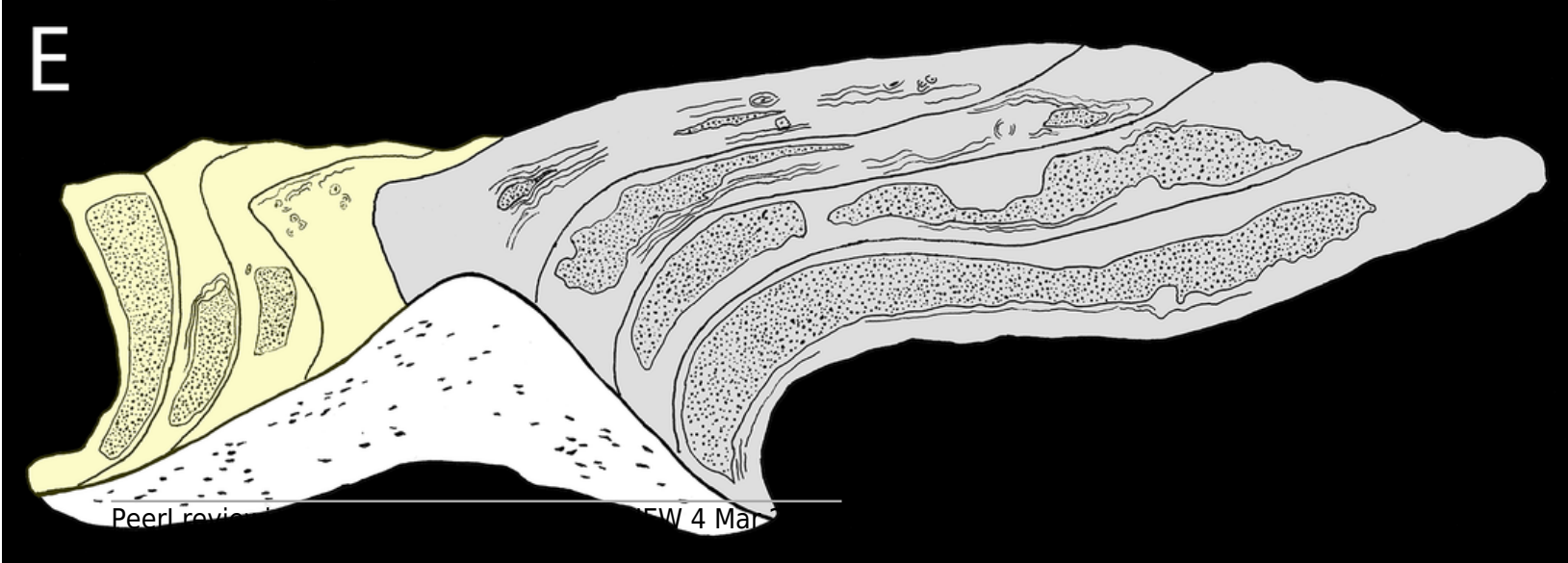

